\title{
Exercise and Use of Enhancement Drugs at the Time of the COVID-19 Pandemic: A Multicultural Study on Coping Strategies During Self-Isolation and Related Risks
}

OPEN ACCESS

Edited by:

Carlos Roncero,

University of Salamanca, Spain

Reviewed by:

Carlos Llanes-Álvarez,

Complejo Asistencial de

Zamora, Spain

Marianna Mazza,

Catholic University of the Sacred

Heart, Italy

*Correspondence:

Artemisa R. Dores

artemisa@ess.ipp.pt

Specialty section:

This article was submitted to Addictive Disorders,

a section of the journal

Frontiers in Psychiatry

Received: 31 December 2020

Accepted: 01 February 2021

Published: 10 March 2021

Citation:

Dores AR, Carvalho IP, Burkauskas J,

Simonato P, De Luca I, Mooney R,

loannidis K, Gómez-Martínez MÁ,

Demetrovics Z, Ábel KE, Szabo A,

Fujiwara $H$, Shibata $M$, Ventola $A R M$,

Arroyo-Anlló EM,

Santos-Labrador RM,

Griskova-Bulanova I,

Pranckeviciene A, Kobayashi K Martinotti G, Fineberg NA, Barbosa F and Corazza O (2021) Exercise and Use of Enhancement Drugs at the

Time of the COVID-19 Pandemic: A

Multicultural Study on Coping Strategies During Self-Isolation and

Related Risks.

Front. Psychiatry 12:648501.

doi: 10.3389/fpsyt.2021.648501
Artemisa R. Dores ${ }^{1,2 *}$, Irene P. Carvalho ${ }^{3}$, Julius Burkauskas ${ }^{4}$, Pierluigi Simonato ${ }^{5}$, Ilaria De Luca ${ }^{5}$, Roisin Mooney ${ }^{6}$, Konstantinos loannidis ${ }^{7,8}$, M. Ángeles Gómez-Martínez ${ }^{9}$, Zsolt Demetrovics ${ }^{10,11}$, Krisztina Edina Ábel ${ }^{10}$, Attila Szabo ${ }^{10,12}$, Hironobu Fujiwara ${ }^{13,14}$, Mami Shibata ${ }^{13}$, Alejandra Rebeca Melero Ventola ${ }^{15}$, Eva Maria Arroyo-Anlló ${ }^{16}$, Ricardo M. Santos-Labrador ${ }^{17}$, Inga Griskova-Bulanova ${ }^{18}$, Aiste Pranckeviciene ${ }^{4}$, Kei Kobayashi ${ }^{13}$, Giovanni Martinotti ${ }^{5,19}$, Naomi A. Fineberg ${ }^{5}$, Fernando Barbosa ${ }^{1}$ and Ornella Corazza ${ }^{5,20}$

${ }^{1}$ Laboratory of Neuropsychophysiology, Faculty of Psychology and Education Sciences, University of Porto, Porto, Portugal, ${ }^{2}$ School of Health, Polytechnic of Porto, Porto, Portugal, ${ }^{3}$ Clinical Neurosciences and Mental Health Department and CINTESIS, School of Medicine, Porto, Portugal, ${ }^{4}$ Laboratory of Behavioral Medicine, Neuroscience Institute, Lithuanian University of Health Sciences, Kaunas, Lithuania, ${ }^{5}$ Department of Clinical, Pharmaceutical and Biological Sciences, School of Life and Medical Sciences, University of Hertfordshire, Hatfield, United Kingdom, ${ }^{6}$ Medical Sciences Division, Department of Psychiatry, University of Oxford, Oxford, United Kingdom, ${ }^{7}$ Department of Psychiatry, University of Cambridge, Cambridge, United Kingdom, ${ }^{8}$ Cambridge and Peterborough NHS Foundation Trust, Cambridge, United Kingdom, ${ }^{9}$ Department of Psychology, Pontifical University of Salamanca, Salamanca, Spain, ${ }^{10}$ Institute of Psychology, ELTE Eötvös Loránd University, Budapest, Hungary, ${ }^{11}$ Centre of Excellence in Responsible Gaming, University of Gibraltar, Gibraltar, ${ }^{12}$ Institute of Health Promotion and Sport Sciences, ELTE Eötvös Loránd University, Budapest, Hungary, ${ }^{13}$ Department of Neuropsychiatry, Graduate School of Medicine, University of Kyoto, Kyoto, Japan, ${ }^{14}$ Artificial Intelligence Ethics and Society Team, RIKEN Center for Advanced Intelligence Project, Saitama, Japan, ${ }^{15}$ Faculty of Psychology, Pontifical University of Salamanca, Salamanca, Spain, ${ }^{16}$ Department of Psychobiology, Neuroscience Institute of Castilla-León, University of Salamanca, Salamanca, Spain, ${ }^{17}$ Department of Physical Education, University Teacher's College 'Fray Luis de León', Valladolid, Spain, ${ }^{18}$ Department of Neurobiology and Biophysics, Institute of Biosciences, Vilnius University, Vilnius, Lithuania, ${ }^{19}$ Department of Neuroscience, Imaging, and Clinical Science "G. d'Annunzio" University of Chieti-Pescara, Chieti, Italy, ${ }^{20}$ Department of Psychology and Cognitive Science, University of Trento, Trento, Italy

Introduction: Little is known about the impact of restrictive measures during the COVID-19 pandemic on self-image and engagement in exercise and other coping strategies alongside the use of image and performance-enhancing drugs (IPEDs) to boost performance and appearance.

Objectives: To assess the role of anxiety about appearance and self-compassion on the practice of physical exercise and use of IPEDs during lockdown.

Methods: An international online questionnaire was carried out using the Exercise Addiction Inventory (EAl), the Appearance Anxiety Inventory (AAl), and the SelfCompassion Scale (SCS) in addition to questions on the use of IPEDs.

Results: The sample consisted of 3,161 (65\% female) adults from Italy (41.1\%), Spain (15.7\%), the United Kingdom (UK) (12.0\%), Lithuania (11.6\%), Portugal (10.5\%), Japan (5.5\%), and Hungary (3.5\%). The mean age was 35.05 years $(S D=12.10)$. Overall, $4.3 \%$ of the participants were found to engage in excessive or problematic exercise with peaks registered in the UK (11.0\%) and Spain (5.4\%). The sample reported the use of a wide 
range of drugs and medicines to boost image and performance (28\%) and maintained use during the lockdown, mostly in Hungary (56.6\%), Japan (46.8\%), and the UK (33.8\%), with $6.4 \%$ who started to use a new drug. Significant appearance anxiety levels were found across the sample, with $18.1 \%$ in Italy, $16.9 \%$ in Japan, and $16.7 \%$ in Portugal. Logistic regression models revealed a strong association between physical exercise and IPED use. Anxiety about appearance also significantly increased the probability of using IPEDs. However, self-compassion did not significantly predict such behavior. Anxiety about appearance and self-compassion were non-significant predictors associated with engaging in physical exercise.

Discussion and Conclusion: This study identified risks of problematic exercising and appearance anxiety among the general population during the COVID-19 lockdown period across all the participating countries with significant gender differences. Such behaviors were positively associated with the unsupervised use of IPEDs, although no interaction between physical exercise and appearance anxiety was observed. Further considerations are needed to explore the impact of socially restrictive measures among vulnerable groups, and the implementation of more targeted responses.

Keywords: compulsive exercise, performance-enhancing substances, body image, body dysmorphic disorders, obsessive-compulsive disorder

\section{INTRODUCTION}

On March 11, 2020, the World Health Organization declared the coronavirus disease 2019 (COVID-19) outbreak to be a pandemic situation as a result of the severe acute respiratory syndrome associated with the coronavirus 2 (SARS-CoV-2) and its highly contagious nature (1). This virus can affect the immune response and, in addition to respiratory complications (2), can have adverse effects on brain function and mental health $(3,4)$.

Since then, governments, health authorities, and citizens have adopted several measures to combat the spread of the virus $(1,5-7)$. These included physical distancing (also known as social distancing), prophylactic isolation, mandatory lockdown, and mandatory quarantine (8), leading to altered lifestyles and habits and affecting millions of individuals worldwide (9), society $(10,11)$, and the economy $(12-14)$. For example, exposure to chronic and daily stressors such as quarantine can affect the cardiovascular system and the emotional experience of the individual, leading to an increased risk of developing a cardiovascular disease or mental illness (15).

Such changes could lead to distress or impairment of citizens' physical, social, and occupational domains (16), generating risk conditions that potentially affect the mental well-being of the general population, especially of those who are most exposed and vulnerable, such as patients diagnosed with COVID-19, those who have been in quarantine or other forms of social isolation, frontline healthcare providers $[(6,17,18)$; for a review $]$, and possibly other key workers (i.e., those workers who are crucial to keeping the country running safely, such as police officers, journalists, people delivering food and transportation).

Some of these measures are not new and have been implemented during other outbreaks in the past, such as severe acute respiratory syndrome (SARS), Middle East respiratory syndrome-related coronavirus (MERS), or Ebola (19, 20). However, the global occurrence of this pandemic might intensify the already known effects of both the pandemic and the sanitary control measures on individuals' mental health (21), warranting additional studies (22).

The potentially addictive nature of physical exercise has received increasing interest in the mental health literature (2330). Social pressure to have a perfect body as a synonym of personal value and success, particularly in Western societies, is transforming the value and meaning attributed to the practice of exercise. Exercise is being increasingly used as a path to boost appearance, rather than primarily as a path to health, or as a pleasurable activity in itself $(23,30)$. Social media have been contributing to such a "fitspirational" trend, namely, through the continuous posting of photos and videos displaying "perfect bodies," or inspirational messages encouraging exercising, often beyond the human physical limits (31-34). Such potential damaging content might have an increased effect on adolescents and individuals with mental health problems (35), who might feel unable to meet such unrealistic beauty ideals. Physical exercise can thus become excessive and even problematic, depending also on the way in which people experience their bodies $(36,37)$.

Excessive and problematic physical exercise, sometimes called "compulsive exercise," "excessive exercising," (38) or "exercise addiction" (EA) (24), is a matter of increasing global concern (23).

Brown's (39) and, more recently, Griffith's six components of addiction (25-27) (i.e., salience, mood modification, tolerance, withdrawal symptoms, conflict, relapse) have been used to distinguish EA from other situations in which the individuals are only highly committed to exercising (38). However, as a controversial term, the construct of EA has not been included in the section of behavioral addictions of the main manuals of 
mental disorders [e.g., the International Classification of Diseases 11th Revision (40) and the Diagnostic and Statistical Manual of Mental Disorders, 5th Edition (DSM-5) (41)], calling for the need of additional sound theory-driven research and clinical evidence that clarify its nature and manifestations.

The relationship between problematic exercise and gender has been inconsistent. Some studies show higher exercise dependence among males (42-44), and others suggest the opposite (45, 46). The association between problematic exercise and age has also been contradictory. Whereas, adulthood has been considered a critical age period for developing problematic exercise in some studies (47), previous studies have reported that the prevalence of exercise dependence should decline with age, or that older adults are less at risk for exercise dependence $(42,48,49)$. These differences across studies are possibly explained by methodological issues (e.g., instruments used, sample characteristics comprising mainly college students). Exercise dependence might have changed over time as well, suggesting the need for both longitudinal and current studies with diverse populations (47).

Problematic exercise has been associated with the escalating consumption of image and performance-enhancing drugs (IPEDs) (23), also known as lifestyle drugs, "an umbrella term that encompasses a variety of different products including anabolic steroids, sexual enhancers, growth hormones, and other drugs that can alter the functions of the body to enhance muscle growth, reduce body fat, and promote weight loss" [(50) cit in 29, p. 2]. IPEDs refer to a wide range of products, which are presented as having the potential to improve mental and physical functions. They include drugs for enhancing muscle structure and function (i.e., anabolic drugs), for weight loss, for modifying the aging process, beauty, and cosmetic appearance (i.e., image-enhancing drugs), for improving sex performance [i.e., "sex drugs," aphrodisiacs, or phosphodiesterase type 5 (PDE5) inhibitors], cognitive performance (i.e., cognitive enhancers), among other functions (23). Online and TV advertisements are contributing to, and exacerbating, the use of these drugs through misleading marketing strategies that promise rapid and safe appearance, physical and mental improvement, and as alternatives to gold standard pharmaceutical products (5155). However, IPEDs might contain undisclosed ingredients with potential damaging effects to unaware users.

Dissatisfaction with one's own body image and related anxiety about one's appearance might further motivate such a hazardous intake with the purpose of improving physical and mental wellbeing. In extreme cases, anxiety about appearance might be symptomatic of body dysmorphic disorder (BDD) (23). BDD, classified under the DSM-5's Obsessive-Compulsive and Related Disorders (41), is characterized by extreme dissatisfaction with minor irregularities in one's appearance alongside the irresistible urge to act to eradicate these irregularities. In males, BDD often takes the form of muscle dysmorphia, where the dissatisfaction focuses on aspects of physique that the individual attempts to remediate through the compulsive use of muscle-enhancing agents and physical exercise (23). BDD has been associated with other clinical conditions, including obsessive-compulsive disorder, eating disorders, and addictive behaviors $(56,57)$.
BDD causes considerable distress and interferes significantly with physical and social functioning $(41,58,59)$. Yet, it is an under-recognized and underdiagnosed condition (59), namely, because people suffering from it rarely seek intervention for the condition itself, rather for the perceived flaws or for the related mental disorders (e.g., addictive behaviors). Although the specific etiology and pathophysiology of BDD are still under debate, within the spectrum of severe obsessive-compulsive behaviors [e.g., (56)], this is one of the most likely mental disorders to manifest alongside both problematic exercise and the use of IPEDs (23).

In contrast, other types of psychological functioning, if present, might contribute to mitigate or prevent the excessive use of physical exercise and IPEDs. For example, self-compassion is involved in emotional self-regulation and has been associated with psychological benefits among young adults (60). This understanding attitude toward oneself is associated with selfacceptance and self-nurturing abilities and therefore might act as a buffer in a number of mental disorders (61).

Considering the restricted activity associated with the COVID-19 pandemic (e.g., closure of gyms), social distancing might also be expected to be beneficial as much as by reducing several of the most frequent everyday stressors (62), individuals may be induced to relax their exercise habits and compulsive need for IPEDs and the anxiety about body image may be reduced. However, to date, young adults have rated everyday events as more intensely stressful during physical isolation (62). Therefore, the lack of physical contact with support networks might conversely trigger additional mental health problems as a result of the quarantine $(16,17,21)$. Prolonged exposure to TV and online information and advertisements during confinement might have also had an impact on people's mood, image, performance, physical exercise, and IPEDs consumption.

In this work, we investigate the impact of the socially restrictive measures imposed by the COVID-19 pandemic on self-image and the practice of excessive, or even potentially problematic, physical exercise and the use of IPEDs as coping strategies to boost appearance during the period of its most restrictive policies (April-May 2020). We also consider the role of self-compassion as a potential mitigating factor for such risky behaviors. Considering the unprecedented situation, we hypothesized that individuals might have engaged more compulsively with exercise and IPEDs intake to better cope with the pandemic's altered lifestyle, closure of fitness centers, and reiterated period of self-isolation $(63,64)$, mainly when selfdirected negative feelings, such as anxiety about one's own body, came into play.

The hypothesis is partly based on the results of a pre-COVID19 investigation where authors found a strong association between "exercise addiction," IPEDs use, including illicit drugs, and BDD among a large international cohort of regular exercisers (23). Evidence was supported by another more recent study on "exercise addiction" during the COVID-19 pandemic among a Spanish-speaking sporting population (65). Although the overall practice of exercise decreased by almost $50 \%$ during the pandemic, the perceived impact of the pandemic on regular exercising did not differ among the three exercise groups 
(asymptomatic, symptomatic, and at-risk for addiction). The risk of "exercise addiction" was found in $\sim 15 \%$ of the sample. As both these studies were carried out among a population of physically active individuals, who exercise on a regular basis, one might wonder about the behaviors across the general population under such extraordinary circumstances. While some individuals were prohibited from practicing their regular physical exercise/activity outdoors (12) and might have stopped their exercise practices, others might have implemented new (unsupervised) workout regimes indoors (66).

More specifically, in this work, we sought: (1) to characterize the practice of physical exercise, (2) to explore the use of IPEDs, and (3) any potential associations between these risky behaviors and self-directed negative feelings of appearance anxiety vs. the positive feelings of self-compassion, along with gender, age, occupation (e.g., key workers) during the start of the COVID-19 pandemic. Results were compared cross-culturally in the United Kingdom (UK), Italy, Hungary, Portugal, Spain, Lithuania, and Japan.

\section{MATERIALS AND METHODS}

\section{Study Design}

This is an international cross-sectional observational study.

\section{Participants}

The sample comprised 3,161 participants from seven countries: Italy $(n=1,300 ; 41.1 \%)$, Spain $(n=497 ; 15.7 \%)$, UK $(n$ $=378 ; 12.0 \%)$, Lithuania $(n=367 ; 11.6 \%)$, Portugal $(n=$ $332 ; 10.5 \%)$, Japan ( $n=175 ; 5.5 \%)$, and Hungary $(n=112$; $3.5 \%)$. Table 1 shows the sociodemographic characteristics of the participants in total and by country. The age of the participants ranged from 15 to 80 years old $(M=35.05 ; S D=12.10)$, and the majority was female $(n=2,046 ; 65.2 \%)$. Most of the sample were highly educated with a master's $(n=995$; $31.6 \%)$, PhD ( $n=196 ; 6.2 \%)$, or a bachelor's degree $(n=951$; $30.2 \%)$ and employed $(n=1,749 ; 55.7 \%)$ or studying $(n=$ $666 ; 21.2 \%)$.

A considerable number of participants were "key workers" $(n=1,106 ; 35.0 \%)$, most of them in health professions $(n=$ $517 ; 16.4 \%)$.

A total of 564 participants reported mental health problems before the pandemic (17.4\%). Anxiety was the most prevalent of the reported mental problems $(n=329$; $10.5 \%)$, followed by depression ( $n=152 ; 4.8 \%)$. Almost half of the participants who reported the presence of a mental disorder before the pandemic considered that the physical distancing has worsened their mental problem $(n=205 ; 47.9 \%)$.

Most of the participants engaged in fitness activities, mainly generic workouts $(n=1,018 ; 33.1 \%)$, running $(n=422 ; 13.7 \%)$, walking ( $n=416 ; 13.5 \%$ ), fight sports (e.g., boxing, kickboxing, judo, sumo, and karate) $(n=412 ; 13.4 \%)$, and martial arts (e.g., aikido, Brazilian Jiu-Jitsu, Krav Maga, Kung Fu) $(n=355 ; 11.5 \%)$. A small proportion of the respondents did not practice physical exercise $(n=422 ; 14.7 \%)$.

\section{Procedure}

The study was approved by the Human Sciences Ethics Committee at the University of Hertfordshire (HSK/SF/UH/00104) and by the Ethics Committees of each participating country. It complied with the Declaration of Helsinki and with the European General Data Protection Regulation. The study's presentation included the project's description and aims, followed by an informed consent form. Upon agreement to participate, a link to the questionnaire was sent to participants. The latter was translated and backtranslated from English into different languages (Italian, Spanish, Japanese, Portuguese, Hungarian, Lithuanian). Data collection was implemented via the Web-based survey platform Qualtrics [Qualtrics, Provo, UT, 2020], and the data were stored in a secure platform at the University of Hertfordshire.

Recruitment was supported by an already established global network of collaborators in Italy, UK, Lithuania, Hungary, Portugal, Spain, and Japan. It mainly occurred via posts on health and well-being social media platforms, not necessarily fitness related, namely, Facebook, LinkedIn, WhatsApp, Twitter, and Instagram. A snowball sampling technique was used; participants were invited to complete the survey and share it with their contacts. These procedures ensured a heterogeneous sample inclusive of both sporting and non-sporting populations.

Data collection occurred during April and May 2020, precisely at the peak of the COVID-19 pandemic and coinciding with the lockdown period in all the participating countries.

\section{Instruments}

The questionnaire was composed of: (a) sociodemographic information; (b) the Exercise Addiction Inventory (EAI); (c) questions on the use of IPEDs (i.e., "Have you taken supplements/products to reach your fitness goal/physical appearance during self-isolation? [Choose yes or no]"; "What are they? [Tick as many as apply]"); (d) the Appearance Anxiety Inventory (AAI); and (e) the Self-Compassion Scale (SCS).

The EAI-brief $(67,68)$ was developed to assess the level of engagement in physical activity. The EAI-brief is based on a modified version of the components of behavioral addiction by Griffiths (24) and consists of six questions that reflect the six general components of addiction (i.e., salience, mood modification, tolerance, withdrawal symptoms, social conflict, and relapse). Participants rate their responses on a 5-point Likert scale ranging from 1 (strongly disagree) to 5 (strongly agree). A sum score is calculated (for a maximum of 30 points), with higher scores indicating the presence of more problems. A score equal to 24 or higher indicates problematic exercise akin to addiction. This cutoff represents those individuals with scores in the top $15 \%$ of the total scale score in the original study. The EAI is a theoretically driven instrument with valid and reliable psychometric properties reported in several studies across many countries (68-70). In our sample, Cronbach's alpha was 0.72, ranging from 0.65 to 0.75 for the different countries.

The intake of a wide range of IPEDs was assessed with questions developed for the purposes of this study. For each question, respondents answered "yes" or "no" or selected the response from a list of options. For purposes 
TABLE 1 | Sociodemographic characteristics of the sample and types of physical activities $(N=3,161)$.

\begin{tabular}{|c|c|c|c|c|c|c|c|c|}
\hline & $\begin{array}{c}\text { Total } \\
N=3,161\end{array}$ & $\begin{array}{c}\text { UK } \\
N=378\end{array}$ & $\begin{array}{c}\text { Italy } \\
N=1,300\end{array}$ & $\begin{array}{c}\text { Spain } \\
N=497\end{array}$ & $\begin{array}{l}\text { Hungary } \\
N=112\end{array}$ & $\begin{array}{l}\text { Portugal } \\
N=332\end{array}$ & $\begin{array}{c}\text { Japan } \\
N=175\end{array}$ & $\begin{array}{l}\text { Lithuania } \\
N=367\end{array}$ \\
\hline \multicolumn{9}{|l|}{ Age, years } \\
\hline Mean & 35.05 & 36.70 & 31.89 & 38.58 & 41.79 & 34.24 & 39.28 & 36.36 \\
\hline (SD) & (12.10) & (12.24) & (10.96) & (13.56) & (11.80) & (11.18) & (13.84) & (10.33) \\
\hline Min-Max & $15-80$ & $15-75$ & $16-80$ & $15-72$ & $18-66$ & $18-65$ & $18-80$ & $16-66$ \\
\hline Gender, Female & 2,046 & 188 & 857 & 302 & 69 & 249 & 70 & 311 \\
\hline$(n ; \%)$ & $65.2 \%$ & $50.7 \%$ & $66.1 \%$ & $61.6 \%$ & $61.6 \%$ & $76.4 \%$ & $40.2 \%$ & $84.7 \%$ \\
\hline \multicolumn{9}{|l|}{ Education level ( $n ; \%)$} \\
\hline PhD & $196(6.2 \%)$ & 44 (11.7\%) & 27 (2.1\%) & $25(5.1 \%)$ & $3(2.7 \%)$ & $22(6.7 \%)$ & 17 (9.7\%) & 58 (15.8\%) \\
\hline Master's degree & 995 (31.6\%) & 140 (37.3\%) & 418 (32.2\%) & $81(16.4 \%)$ & 41 (36.6\%) & 97 (29.4\%) & $21(12.0 \%)$ & 197 (53.7\%) \\
\hline Bachelor's degree & 951 (30.2\%) & $118(31.5 \%)$ & 262 (20.2\%) & $240(48.7 \%)$ & 24 (21.4\%) & $152(46.1 \%)$ & 89 (50.9\%) & $6618.0 \%$ \\
\hline High school & $760(24.1 \%)$ & 50 (13.3\%) & 520 (40.0\%) & $32(6.5 \%)$ & $31(27.7 \%)$ & 55 (16.7\%) & $36(20.6 \%)$ & 36 (9.8\%) \\
\hline Other & 249 (7.9\%) & $23(6.1 \%)$ & $72(5.5 \%)$ & $115(23.3 \%)$ & $13(11.6 \%)$ & $4(1.2 \%)$ & $12(6.9 \%)$ & $10(2.7 \%)$ \\
\hline \multicolumn{9}{|l|}{ Occupation ( $n ; \%)$} \\
\hline Employed & 1,749 (55.7\%) & 231 (61.4\%) & $659(51.0 \%)$ & $248(50.3 \%)$ & 74 (66.1\%) & $136(41.3 \%)$ & $122(70.1 \%)$ & 279 (76.6\%) \\
\hline Student & $666(21.2 \%)$ & 60 (16.0\%) & 332 (25.7\%) & $98(19.9 \%)$ & $9(8.0 \%)$ & 88 (26.7\%) & 37 (21.3\%) & 42 (11.5\%) \\
\hline Unemployed & 244 (7.8\%) & $13(3.5 \%)$ & $132(10.2 \%)$ & $53(10.8 \%)$ & $6(5.4 \%)$ & $25(7.6 \%)$ & 5 (2.9\%) & $10(2.7 \%)$ \\
\hline Retired & $200(6.4 \%)$ & $9(2.4 \%)$ & $153(11.8 \%)$ & $25(5.1 \%)$ & 4 (3.6\%) & 7 (2.1\%) & $0(0 \%)$ & 2 (0.5\%) \\
\hline $\begin{array}{l}\text { Freelance/individual } \\
\text { activity }\end{array}$ & $282(9.0 \%)$ & $63(16.8 \%)$ & $17(1.3 \%)$ & $69(14.0 \%)$ & $19(17.0 \%)$ & $73(22.2 \%)$ & $10(5.7 \%)$ & $31(8.5 \%)$ \\
\hline Key worker (n; \%) & 1,102 (34.9\%) & $103(27.4 \%)$ & 392 (30.2\%) & $170(34.2 \%)$ & 48 (42.9\%) & 111 (33.6\%) & 98 (56.0\%) & 180 (49.0\%) \\
\hline $\begin{array}{l}\text { Health care and related } \\
\text { specialities }\end{array}$ & $517(16.4 \%)$ & 52 (13.8\%) & 186 (14.3\%) & $69(13.9 \%)$ & 9 (8.0\%) & 65 (19.7\%) & 57 (32.6\%) & 79 (21.5\%) \\
\hline Teachers and tutors & $90(2.9 \%)$ & $8(2.1 \%)$ & $15(1.2 \%)$ & $5(1.0 \%)$ & 10 (8.9\%) & $8(2.1 \%)$ & $20(11.4 \%)$ & 25 (6.8\%) \\
\hline Transportation & $23(0.7 \%)$ & 3 (0.8\%) & $5(0.4 \%)$ & $4(0.8 \%)$ & $5(4.5 \%)$ & $2(0.6 \%)$ & $2(1.1 \%)$ & 2 (0.5\%) \\
\hline Food industry & $69(2.2 \%)$ & 7 (1.9\%) & $20(1.5 \%)$ & $24(4.8 \%)$ & $3(2.7 \%)$ & $1(0.3 \%)$ & $2(1.1 \%)$ & 12 (3.3\%) \\
\hline Public sector & $32(1.0 \%)$ & $4(1.1 \%)$ & $2(0.2 \%)$ & $12(2.4 \%)$ & $1(0.9 \%)$ & $4(1.2 \%)$ & $3(1.7 \%)$ & $6(1.6 \%)$ \\
\hline Government & 59 (1.9\%) & $6(1.6 \%)$ & $22(1.7 \%)$ & $8(1.6 \%)$ & $1(0.9 \%)$ & $5(1.5 \%)$ & 2 (1.1\%) & 15 (4.1\%) \\
\hline $\begin{array}{l}\text { Postal and other } \\
\text { services }\end{array}$ & $34(1.1 \%)$ & $1(0.3 \%)$ & $16(1.2 \%)$ & $13(2.6 \%)$ & $3(2.7 \%)$ & $0(0 \%)$ & $0(0 \%)$ & $1(0.3 \%)$ \\
\hline $\begin{array}{l}\text { National or public } \\
\text { security }\end{array}$ & 40 (1.3\%) & $7(1.9 \%)$ & $9(0.7 \%)$ & 10 (2.0\%) & 1 (0.9\%) & $2(0.6 \%)$ & $4(2.3 \%)$ & $7(1.9 \%)$ \\
\hline $\begin{array}{l}\text { Pharmacy and related } \\
\text { activity }\end{array}$ & $23(0.7 \%)$ & $3(0.8 \%)$ & $11(0.8 \%)$ & $4(0.8 \%)$ & $1(0.9 \%)$ & $2(0.6 \%)$ & $1(0.6 \%)$ & $1(0.3 \%)$ \\
\hline Other & 187 (5.9\%) & $23(6.1 \%)$ & $71(5.5 \%)$ & $0(0 \%)$ & $19(17.0 \%)$ & $71(5.5 \%)$ & $6(3.4 \%)$ & 50 (13.6\%) \\
\hline Professional athlete & $52(1.6 \%)$ & $6(1.6 \%)$ & $28(2.2 \%)$ & $3(0.6 \%)$ & $3(2.7 \%)$ & $5(1.5 \%)$ & $0(0 \%)$ & 7 (1.9\%) \\
\hline Mental disorder (before) & 547 (17.4\%) & 76 (20.2\%) & 257 (19.9\%) & $89(17.9 \%)$ & $12(10.7 \%)$ & 67 (20.3\%) & $14(8.0 \%)$ & 32 (8.8\%) \\
\hline Anxiety & 329 (10.5\%) & $58(15.4 \%)$ & 128 (9.9\%) & $71(14.3 \%)$ & 7 (6.3\%) & 39 (11.8\%) & $4(2.3 \%)$ & 22 (6.0\%) \\
\hline Depression & $152(4.8 \%)$ & 44 (11.7\%) & $54(4.2 \%)$ & $19(3.8 \%)$ & $6(5.4 \%)$ & $13(3.9 \%)$ & $1(0.6 \%)$ & 15 (4.1\%) \\
\hline Other mood disorders & $52(1.7 \%)$ & 7 (1.9\%) & $21(1.6 \%)$ & $11(2.2 \%)$ & $2(1.8 \%)$ & 7 (2.1\%) & $3(1.7 \%)$ & $1(0.3 \%)$ \\
\hline Psychotic disorders & $7(0.2 \%)$ & 5 (1.3\%) & $0(0 \%)$ & $0(0 \%)$ & $0(0 \%)$ & $1(0.3 \%)$ & $0(0 \%)$ & $1(0.3 \%)$ \\
\hline Eating disorders & $73(2.3 \%)$ & $16(4.3 \%)$ & $30(2.3 \%)$ & $14(2.8 \%)$ & $2(1.8 \%)$ & $3(0.9 \%)$ & $1(0.6 \%)$ & 7 (1.9\%) \\
\hline Personality disorders & $15(0.5 \%)$ & $6(1.6 \%)$ & $6(0.5 \%)$ & $2(0.4 \%)$ & $0(0 \%)$ & $0(0 \%)$ & $0(0 \%)$ & 1 (0.3\%) \\
\hline Other(s) & $87(2.8 \%)$ & $10(2.7 \%)$ & 37 (2.9\%) & $10(2.0 \%)$ & $6(1.8 \%)$ & $2(1.8 \%)$ & $6(3.4 \%)$ & $16(4.4 \%)$ \\
\hline $\begin{array}{l}\text { Physical distancing } \\
\text { worsened mental } \\
\text { disorder }\end{array}$ & 205 (47.9\%) & 26 (44.8\%) & 97 (45.1\%) & 27 (47.4\%) & $3(33.3 \%)$ & 32 (64.0\%) & $5(55.6 \%)$ & 15 (50.0\%) \\
\hline \multicolumn{9}{|l|}{ Physical exercise } \\
\hline Generic workout & 1,018 (33.1\%) & $112(29.9 \%)$ & 442 (35.0\%) & $145(29.7 \%)$ & 27 (24.3\%) & 124 (38.5\%) & 15 (9.2\%) & $153(42.7 \%)$ \\
\hline Running & 422 (13.7\%) & 69 (18.4\%) & 165 (13.1\%) & 66 (13.5\%) & 31 (27.9\%) & 33 (10.2\%) & 21 (12.9\%) & 37 (10.3\%) \\
\hline Walking & 416 (13.5\%) & 42 (11.2\%) & 133 (10.5\%) & $122(25.0 \%)$ & $6(5.4 \%)$ & 48 (14.9\%) & $15(9.2 \%)$ & 50 (14.0\%) \\
\hline Fighting sports & 412 (13.4\%) & 188 (50.3\%) & 85 (6.7\%) & 33 (6.8\%) & $2(1.8 \%)$ & $8(2.5 \%)$ & 84 (51.5\%) & $12(3.4 \%)$ \\
\hline
\end{tabular}


TABLE 1 | Continued

\begin{tabular}{|c|c|c|c|c|c|c|c|c|}
\hline & $\begin{array}{c}\text { Total } \\
N=3,161\end{array}$ & $\begin{array}{c}\text { UK } \\
N=378\end{array}$ & $\begin{array}{c}\text { Italy } \\
N=1,300\end{array}$ & $\begin{array}{c}\text { Spain } \\
N=497\end{array}$ & $\begin{array}{l}\text { Hungary } \\
N=112\end{array}$ & $\begin{array}{l}\text { Portugal } \\
N=332\end{array}$ & $\begin{array}{c}\text { Japan } \\
N=175\end{array}$ & $\begin{array}{c}\text { Lithuania } \\
N=367\end{array}$ \\
\hline Martial arts & 355 (11.5\%) & 181 (48.4\%) & 42 (3.3\%) & 30 (6.1\%) & 1 (0.9\%) & $6(1.9 \%)$ & 83 (50.9\%) & $12(3.4 \%)$ \\
\hline Yoga & 306 (9.9\%) & 47 (12.6\%) & $110(8.7 \%)$ & 43 (8.8\%) & 15 (13.5\%) & 31 (9.6\%) & $14(8.6 \%)$ & 46 (12.8\%) \\
\hline Swimming & 216 (7.0\%) & $26(7.0 \%)$ & 90 (7.1\%) & 24 (4.9\%) & 32 (28.8\%) & 17 (5.3\%) & 8 (4.9\%) & 19 (5.3\%) \\
\hline Weight lifting & 210 (6.8\%) & 32 (8.6\%) & 99 (7.8\%) & $10(2.0 \%)$ & 12 (10.8\%) & 26 (8.1\%) & $5(3.1 \%)$ & $26(7.3 \%)$ \\
\hline Cycling & 172 (5.6\%) & 28 (7.5\%) & $64(5.1 \%)$ & 22 (4.5\%) & 18 (16.2\%) & 13 (4.0\%) & $4(2.5 \%)$ & $23(6.4 \%)$ \\
\hline Ball sports & 160 (5.2\%) & $19(5.1 \%)$ & 79 (6.3\%) & 27 (5.5\%) & $8(7.2 \%)$ & 17 (5.3\%) & $3(1.8 \%)$ & 7 (2.0\%) \\
\hline Other & 129 (4.2\%) & 32 (8.6\%) & 48 (3.8\%) & 10 (2.0\%) & $8(7.2 \%)$ & 7 (2.2\%) & 7 (4.3\%) & 17 (4.7\%) \\
\hline Dance & 118 (3.8\%) & 15 (4.0\%) & 49 (3.9\%) & 17 (3.5\%) & $6(5.4 \%)$ & $9(2.8 \%)$ & $2(1.2 \%)$ & $20(5.6 \%)$ \\
\hline Mountaineering & 85 (3.1\%) & 15 (4.0\%) & 38 (3.0\%) & $20(4.1 \%)$ & $6(5.4 \%)$ & - & $1(0.6 \%)$ & $5(1.4 \%)$ \\
\hline Cross fit & $82(2.7 \%)$ & $8(2.1 \%)$ & 32 (2.5\%) & 16 (3.3\%) & $3(2.7 \%)$ & 17 (5.3\%) & $0(0 \%)$ & $6(1.7 \%)$ \\
\hline Tennis & 57 (1.9\%) & 7 (1.9\%) & $8(0.6 \%)$ & 19 (3.9\%) & $6(5.4 \%)$ & $4(1.2 \%)$ & 4 (2.5\%) & 9 (2.5\%) \\
\hline Triathlon & 30 (1.0\%) & 1 (0.3\%) & 25 (2.0\%) & $0(0 \%)$ & 2 (1.8\%) & 1 (0.3\%) & 0 (0\%) & $1(0.3 \%)$ \\
\hline No activity & 452 (14.7\%) & 11 (2.9\%) & 239 (18.9\%) & 67 (13.7\%) & $2(1.8 \%)$ & 51 (15.8\%) & 13 (8.0\%) & 69 (19.3\%) \\
\hline
\end{tabular}

Note: The percentages do not add up to 100 because some people reported more sports they use and more than one key worker job.

of comparison, listed products included all those used in a previous study by Corazza et al. (23), developed after consultation with experts, namely, sport nutritionists and clinicians.

The AAI (71) measures the cognitive and behavioral dimensions of anxiety about body image in general and provides an indication of symptoms associated with BDD. It is a 10 -item self-report questionnaire that assesses the frequency of avoidance behavior and of monitoring threats (e.g., checking, self-focused attention) that are characteristic of responses to a distorted body image. In its original version, each item is rated on a 5-point Likert scale ranging from 0 (not at all) to 4 (all the time), yielding a summary score with a maximum of 40 points. Higher scores indicate a higher occurrence of appearance anxiety. It has been used to assess change in psychotherapy with patients suffering from BDD. In our version, the AAI included a four-point Likert scale ranging from 1 (not at all) to 4 (all the time), for a maximum of 40 points. The cutoff score for this version was defined using the same methodology as for the EAI questionnaire, i.e., values $\geq 21$ based on the scores falling in the top $15 \%$ of the total scale score. In our sample, Cronbach's alpha was 0.87 , ranging from 0.81 to 0.90 for the different countries in this study.

The SCS-Short Form (72) consists of compassion turned to oneself and is related to emotional self-regulation. It consists of 12 items distributed by six subscales: Self-Kindness, SelfJudgment, Common Humanity, Isolation, Mindfulness, and Over-Identification. Respondents are asked to answer each item on a 5 -point scale ranging from 1 (almost never) to 5 (almost always) according to "how I typically act toward myself in difficult times." The total score of the SCS (maximum of 60 points) is computed through the sum of the scores on the six subscales (with some of them being reversed previously). Higher scores indicate greater self-compassion. The SCS lacks an official cutoff score. Consistent with the procedures for the AAI, we used the cutoff score $<27$ to represent those $15 \%$ of the study group who were the least self-compassionate. In our sample, Cronbach's alpha was 0.82 , ranging from 0.80 to 0.84 for the different countries in this study.

\section{Data Analysis}

Normality checking yielded adequate values, and SPSS for Windows, version 17.0 (SPSS Inc., Chicago, Illinois), was used for all analyses.

Descriptive analyses (frequency, central tendency, and dispersion measures) were used for the following variables: sociodemographic characteristics (age, gender, occupation), use of IPEDs and sources where the IPEDs were obtained, the EAI, the AAI, and the SCS. Student's $t$-tests were calculated to compare means on the EAI, AAI, and SCS between male and female participants. Chi-square tests were used for categorical variables, to compare scores (e.g., above/below the cutoff point for each instrument) between male and female participants, and by country.

Binary logistic regressions were calculated to inspect (1) how AAI, SCS, and IPEDs use predict the practice of physical exercise (classified as 0 , "no practice," or 1, "practice"), controlling for age, and (2) how AAI, SCS, and EAI predict IPEDs consumption (classified as 0 , "not used," or 1, "used"), also controlling for age. These same logistic regression models were then run for each gender. In addition, (3) logistic regressions were conducted to inspect reported changes in physical exercise, in IPEDs consumption, and in mental health state during the lockdown (as outcome variables) and the predictors of such changes. A new predictor was entered in these latter models [namely, whether or not respondents were key workers $(0$, "non-key worker"; 1, "key worker")] in addition to the other variables mentioned above [AAI, SCS, IPEDs use, EAI, gender ( 0 , men; 1 , women), and age] for inspection of the role of key workers in these changes. Professional athletes represented a very small proportion of the total sample and were removed from the first regression analysis so that results better reflect the population at large. With a given sample size allowing $R^{2}$ 
TABLE 2 | Problematic exercise (EAI $\geq 24)$ : total and by country.

\begin{tabular}{|c|c|c|c|c|c|c|c|c|c|}
\hline & $\begin{array}{l}\text { Total } \\
n(\%)\end{array}$ & $\begin{array}{c}\text { UK } \\
n(\%) \\
N=363\end{array}$ & $\begin{array}{c}\text { Italy } \\
n(\%) \\
N=1,211\end{array}$ & $\begin{array}{c}\text { Spain } \\
n(\%) \\
N=463\end{array}$ & $\begin{array}{c}\text { Hungary } \\
n(\%) \\
N=107\end{array}$ & $\begin{array}{c}\text { Portugal } \\
n(\%) \\
N=316\end{array}$ & $\begin{array}{c}\text { Japan } \\
n(\%) \\
N=172\end{array}$ & $\begin{array}{c}\text { Lithuania } \\
n(\%) \\
N=337\end{array}$ & $\begin{array}{c}\text { Country } \\
\text { differences }\end{array}$ \\
\hline EAI & 128 & 40 & 37 & 25 & 4 & 9 & 5 & 8 & $\begin{array}{l}\chi^{2}= \\
51.17\end{array}$ \\
\hline (scores $\geq 24$ ) & $(4.3 \%)$ & (11.0\%) & (3.1\%) & (5.4\%) & (3.7\%) & $(2.8 \%)$ & (2.9\%) & $(2.4 \%)$ & $p<0.001$ \\
\hline$n=2,969$ & & & & & & & & & \\
\hline
\end{tabular}

TABLE 3 | Use of fitness supplements (IPEDs): total and by country.

\begin{tabular}{|c|c|c|c|c|c|c|c|c|c|}
\hline & $N 2,684$ & $\begin{array}{c}\text { UK } \\
n(\%)\end{array}$ & $\begin{array}{l}\text { Italy } \\
n(\%)\end{array}$ & $\begin{array}{l}\text { Spain } \\
n(\%)\end{array}$ & $\begin{array}{c}\text { Hungary } \\
n(\%)\end{array}$ & $\begin{array}{l}\text { Portugal } \\
n(\%)\end{array}$ & $\begin{array}{c}\text { Japan } \\
n(\%)\end{array}$ & $\begin{array}{l}\text { Lithuania } \\
n(\%)\end{array}$ & $\begin{array}{c}\text { Country } \\
\text { differences }\end{array}$ \\
\hline Have never used & $\begin{array}{l}1,945 \\
(72.5 \%)\end{array}$ & $\begin{array}{c}219 \\
(66.2 \%)\end{array}$ & $\begin{array}{c}822 \\
(76.2 \%)\end{array}$ & $\begin{array}{c}380 \\
(85.8 \%)\end{array}$ & $\begin{array}{c}34 \\
(44.2 \%)\end{array}$ & $\begin{array}{c}197 \\
(69.1 \%)\end{array}$ & $\begin{array}{c}88 \\
(55.0 \%)\end{array}$ & $\begin{array}{c}205 \\
(66.3 \%)\end{array}$ & \\
\hline Have used & $\begin{array}{l}739 \\
(28.0 \%)\end{array}$ & $\begin{array}{c}112 \\
(33.8 \%)\end{array}$ & $\begin{array}{c}257 \\
(24.3 \%)\end{array}$ & $\begin{array}{c}63 \\
(14.4 \%)\end{array}$ & $\begin{array}{c}43 \\
(56.6 \%)\end{array}$ & $\begin{array}{c}88 \\
(31.5 \%)\end{array}$ & $\begin{array}{c}72 \\
(46.8 \%)\end{array}$ & $\begin{array}{c}104 \\
(34.4 \%)\end{array}$ & $\begin{array}{c}\chi^{2}=118.47 \\
p<0.001\end{array}$ \\
\hline $\begin{array}{l}\text { Used before and } \\
\text { during isolation }\end{array}$ & $\begin{array}{l}528 \\
(19.7 \%)\end{array}$ & $\begin{array}{c}106 \\
(32.0 \%)\end{array}$ & $\begin{array}{c}150 \\
(13.9 \%)\end{array}$ & $\begin{array}{c}38 \\
(8.6 \%)\end{array}$ & $\begin{array}{c}41 \\
(53.2 \%)\end{array}$ & $\begin{array}{c}50 \\
(17.5 \%)\end{array}$ & $\begin{array}{c}66 \\
(41.3 \%)\end{array}$ & $\begin{array}{c}77 \\
(24.9 \%)\end{array}$ & \\
\hline $\begin{array}{l}\text { Used before } \\
\text { isolation, have not } \\
\text { used during } \\
\text { isolation }\end{array}$ & $\begin{array}{l}39 \\
(1.5 \%)\end{array}$ & $\begin{array}{c}2 \\
(0.6 \%)\end{array}$ & $\begin{array}{c}14 \\
(1.3 \%)\end{array}$ & $\begin{array}{c}7 \\
(1.6 \%)\end{array}$ & $\begin{array}{c}2 \\
(2.6 \%)\end{array}$ & $\begin{array}{c}4 \\
(1.4 \%)\end{array}$ & $\begin{array}{c}2 \\
(1.3 \%)\end{array}$ & $\begin{array}{c}8 \\
(2.6 \%)\end{array}$ & \\
\hline $\begin{array}{l}\text { Started using } \\
\text { during isolation }\end{array}$ & $\begin{array}{l}172 \\
(6.4 \%)\end{array}$ & $\begin{array}{c}4 \\
(1.2 \%)\end{array}$ & $\begin{array}{c}93 \\
(8.6 \%)\end{array}$ & $\begin{array}{c}18 \\
(4.1 \%)\end{array}$ & $\begin{array}{c}0 \\
(0.0 \%)\end{array}$ & $\begin{array}{c}34 \\
(11.9 \%)\end{array}$ & $\begin{array}{c}4 \\
(2.5 \%)\end{array}$ & $\begin{array}{c}19 \\
(6.1 \%)\end{array}$ & \\
\hline
\end{tabular}

IPEDs, Image and performance-enhancing drugs.

for a $2 \%$ change and the number of predictor variables ranging from 4 to 7 , we were able to achieve power ranging from 0.74 to 0.99 .

\section{RESULTS}

\section{Physical Exercise}

Among 3,161 participants from seven countries included in this study, results showed a mean score of $16.63(S D=4.32)$ on the EAI, with male participants displaying significantly higher values $(M=16.99 ; S D=4.41)$ than their female counterparts $(M=$ $16.43 ; S D=4.25), t_{(2946)}=3.31 ; p=0.001 ; d=0.13$. Scores equal to or above the cutoff point of 24, indicating problematic exercise akin to addiction, were observed among $4.3 \%(n=128)$ of the total sample. This group of high scorers also included a significantly greater proportion of male $(n=60 ; 5.9 \%)$ than female participants $(n=66 ; 3.4 \%), \chi^{2}(1, N=2,946)=9.58$, $p=0.002 ; N=126$. In addition, major cross-cultural differences were found in the comparison among those scoring above/below the cutoff point of 24 across the participating countries (Table 2). Those at risk of more problematic forms of exercise were mainly found in the UK (11\%) and Spain (5.4\%).

\section{Use of Image and Performance-Enhancing Drugs (IPEDs)}

Just over a quarter of participants $(28 \%, N=2,684)$ had used IPEDs (Table 3). Among them, 19.7\% reported using IPEDs before the restrictive measures and maintaining this behavior during the lockdown; only $1.5 \%$ had stopped consuming IPEDs
(Table 3). In addition, $6.4 \%$ of the total sample started consuming IPEDs during this period.

Major differences emerging from the cross-cultural comparison are displayed in Table 3. Hungary presented the largest percentage of participants who reported using IPEDs (56.6\%), followed by Japan (46.8\%), then Lithuania (34.4\%), the UK (33.8\%), and Portugal (31.5\%).

Those who started the consumption of IPEDs during selfisolation were mainly from Portugal (11.9\%), while those who were already consuming such products and continued during lockdown were mainly from Hungary (53.2\%), Japan (41.3\%), and the UK (32.0\%) (Table 3). A gender difference was found among those who were already using IPEDs before isolation and continued consuming during isolation, $\chi^{2}(2, N=2,618)=$ $40.41, p<0.001 ; N=525$, with a greater proportion of male $(n=$ $241,26.8 \%)$ than female participants $(n=284 ; 16.5 \%)$ reporting continued use.

Across the overall sample, the products that were most frequently used with the purpose of enhancing image and performance were vitamins $(40.5 \%)$, proteins $(40.4 \%)$, caffeine $(36.2 \%)$, tea or infusions $(35.7 \%)$, multivitamin supplements (33.6\%), and amino acids (27.8\%), along with other substances such as ibuprofen (10.3\%) and antioxidants (8.3\%). Participants also reported consumption of stimulants, nitric oxide, beta blockers, and ketones, used by around $2.0 \%$, androgenic substances, namely, steroids and hormones or hormone-related products (each used by $1.4 \%$ of the sample), and other products that were reported in smaller percentages (Table 4). These products were purchased mostly in pharmacies (43.8\%), followed 
TABLE 4 | Use of fitness supplements: type and source of purchase (total and by country).

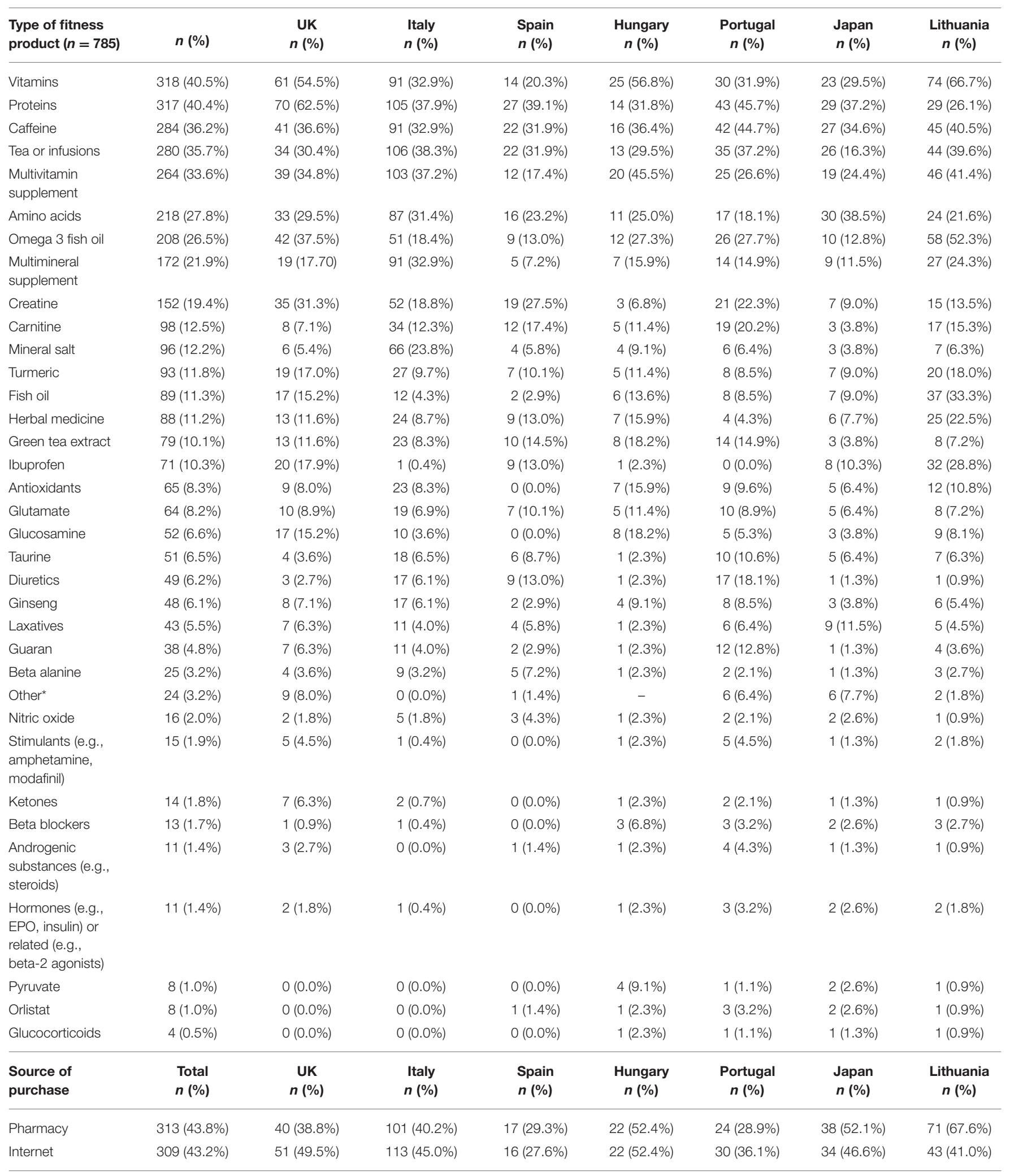


TABLE 4 | Continued

\begin{tabular}{|c|c|c|c|c|c|c|c|c|}
\hline $\begin{array}{l}\text { Type of fitness } \\
\text { product }(n=785)\end{array}$ & $n(\%)$ & $\begin{array}{c}\text { UK } \\
n(\%)\end{array}$ & $\begin{array}{l}\text { Italy } \\
n(\%)\end{array}$ & $\begin{array}{l}\text { Spain } \\
n(\%)\end{array}$ & $\begin{array}{l}\text { Hungary } \\
n(\%)\end{array}$ & $\begin{array}{l}\text { Portugal } \\
n(\%)\end{array}$ & $\begin{array}{l}\text { Japan } \\
n(\%)\end{array}$ & $\begin{array}{l}\text { Lithuania } \\
n(\%)\end{array}$ \\
\hline $\begin{array}{l}\text { Specialized food } \\
\text { store }\end{array}$ & 178 (24.9\%) & 33 (32.0\%) & 58 (23.1\%) & 23 (39.7\%) & 12 (28.6\%) & 30 (36.1\%) & $6(8.2 \%)$ & $16(15.2 \%)$ \\
\hline Food store & 156 (21.8\%) & 33 (32.0\%) & 47 (18.7\%) & 16 (27.6\%) & 5 (11.9\%) & 26 (31.3\%) & 17 (23.3\%) & 12 (11.4\%) \\
\hline Other & 33 (4.6\%) & 4 (3.9\%) & 15 (6.0\%) & 3 (5.2\%) & $3(7.1 \%)$ & 2 (2.4\%) & 3 (4.1\%) & 3 (2.9\%) \\
\hline Black market & $6(0.8 \%)$ & $2(1.9 \%)$ & $1(0.4 \%)$ & $0(0.0 \%)$ & $0(0.0 \%)$ & $2(2.4 \%)$ & $0(0.0 \%)$ & 1 (1.0\%) \\
\hline
\end{tabular}

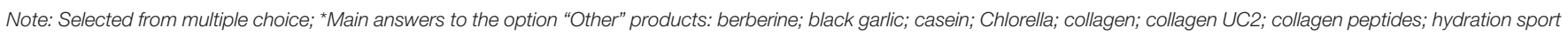
drinks; pea protein isolate. The percentages do not add up to 100 because some people reported more forms of supplements they use.

TABLE 5 | Appearance Anxiety Inventory (AAl) and Self-Compassion Scale (SCS) results per country.

\begin{tabular}{|c|c|c|c|c|c|c|c|c|}
\hline & UK & Italy & Spain & Hungary & Portugal & Japan & Lithuania & $\begin{array}{c}\text { Country } \\
\text { differences }\end{array}$ \\
\hline $\begin{array}{l}\text { AAl (scores } \geq 21) \\
n=2,873\end{array}$ & $\begin{array}{c}45 \\
(12.8 \%)\end{array}$ & $\begin{array}{c}214 \\
(18.1 \%)\end{array}$ & $\begin{array}{c}39 \\
(8.6 \%)\end{array}$ & $\begin{array}{c}15 \\
(15.2 \%)\end{array}$ & $\begin{array}{c}51 \\
(16.7 \%)\end{array}$ & $\begin{array}{c}29 \\
(16.9 \%)\end{array}$ & $\begin{array}{c}48 \\
(14.5 \%)\end{array}$ & $\begin{array}{c}\chi^{2}=25.53 \\
p<0.001\end{array}$ \\
\hline $\begin{array}{l}\text { SCS (scores <27) } \\
n=2,785\end{array}$ & $\begin{array}{c}81 \\
(23.9 \%)\end{array}$ & $\begin{array}{c}278 \\
(24.3 \%)\end{array}$ & $\begin{array}{c}62 \\
(13.9 \%)\end{array}$ & $\begin{array}{c}14 \\
(14.9 \%)\end{array}$ & $\begin{array}{c}32 \\
(10.8 \%)\end{array}$ & $\begin{array}{c}19 \\
(11.2 \%)\end{array}$ & $\begin{array}{c}39 \\
(12.2 \%)\end{array}$ & $\begin{array}{c}\chi^{2}=64.52 \\
p<0.001\end{array}$ \\
\hline
\end{tabular}

$\chi^{2}$, chi-square test.

by the Internet $(43.2 \%)$, and food stores and specialized food stores ( 24.9 and $21.8 \%$, respectively). The category "others" was chosen by $4.6 \%$ of the respondents, and $0.8 \%$ made a purchase from the black market (Table 4). Lithuanians had the highest rates of vitamins, omega 3, and fish oil use as well as positive attitude toward herbal medicine and herbal infusions; the highest prevalence of ibuprofen use was also observed in Lithuania. Participants in Lithuania acquired IPEDs from pharmacies in a very large percentage and larger than respondents from all other countries.

\section{Appearance Anxiety vs. Self-Compassion}

Regarding anxiety about one's appearance, the sample's mean value on the AAI was $15.82(S D=5.11)$. Female participants $(M=16.62 ; S D=5.29)$ scored significantly higher than male participants $(M=14.31 ; S D=4.36), t_{(2872)}=-11.85 ; p<$ $0.001 ; d=0.48$. About $15 \%(n=441)$ of the participants scored 21 or above, which may be indicative of symptom domains associated with BDD. There was a significant relationship between participants' gender and scoring above/below 21. Female participants were more likely than male participants to score 21 or above, $\chi^{2}(2, N=437)=60.60, p<0.001$, indicating that they were more at risk. Analyses by country showed that values above the cutoff point on the AAI registered the highest percentage of participants in Italy (18.1\%), followed by several countries registering similar values (Table 5).

The sample's mean score on the SCS was 31.43 (SD = $5.71)$, with male participants $(M=32.35 ; S D=5.25)$ showing significantly higher values than female participants $(M=30.92$; $S D=5.89), t_{(2784)}=6.55, p<0.001, d=0.26$. The percentage of participants scoring below the cutoff point (i.e., values $<27)$ was $16.6 \%(n=525)$. The chi-square test showed that there was a significant association between gender and scoring above/below 27. Female participants were more likely than their male counterparts to score below $27, \chi^{2}(2, N=523)=$ 29.13, $p<0.001$. The countries with the largest percentages of participants scoring below the cutoff point were Italy and the UK. These two countries registered similar percentages of low scorers (respectively, 24.3 and 23.9\%) and greater percentages than the remaining countries (Table 5).

\section{Predictors of Physical Exercise and of Image and Performance-Enhancing Drugs (IPEDs) Use}

Logistic regression on physical exercise [classified as 0, "no practice," or 1, "practice," according to the question, "Do you practice any sport(s)?"] included IPEDs consumption (0, "not used"; 1 , "used"), AAI scores $(0,<21 ; 1, \geq 21)$, SCS scores $(0,<27$; $1, \geq 27$ ), and age in the model (Table 6). The strongest predictor of physical exercise was IPEDs use, with an odds ratio of 2.507, 95\% CI 1.824-3.445, $p<0.001$. The probability of practicing exercise almost tripled when participants used IPEDs compared to when they did not use them. Age was also significant and was positively related with physical exercise [odds ratio $(\mathrm{OR})=1.014$, 95\% CI 1.003-1.025, $p=0.012$ ]. Appearance anxiety and selfcompassion were non-significant predictors of physical exercise.

Among male participants, the two significant predictors of physical exercising were IPEDs consumption $(\mathrm{OR}=$ $4.165,95 \%$ CI 2.191-7.917, $p<0.001)$ and age $(\mathrm{OR}=$ 1.026, 95\% CI 1.006-1.046, $p=0.012$ ). IPEDs consumption was a strong positive predictor. All else being constant, men who use IPEDs were over four times more likely to practice exercise than not practice it. Among female 
TABLE 6 | Physical exercise logistic regression model (total and by gender).

\begin{tabular}{|c|c|c|c|c|c|c|c|c|c|}
\hline & & \multirow[t]{2}{*}{$B$} & \multirow[t]{2}{*}{ ES } & \multirow[t]{2}{*}{ Wald } & \multirow[t]{2}{*}{ df } & \multirow[t]{2}{*}{$p$} & \multirow{2}{*}{$\begin{array}{c}\text { Odds } \\
\text { ratio } \\
\text { (OR) }\end{array}$} & \multicolumn{2}{|c|}{ Confidence interval (Cl) } \\
\hline & & & & & & & & Min & Max \\
\hline Model I: physical & AAl (scores $\geq 21$ ) & -0.280 & 0.164 & 2.921 & 1 & 0.087 & 0.756 & 0.548 & 1.042 \\
\hline exercise (total & SCS (scores <27) & 0.225 & 0.152 & 2.193 & 1 & 0.139 & 1.252 & 0.930 & 1.687 \\
\hline \multirow[t]{3}{*}{ sample) $N=1,995$} & IPEDs & 0.919 & 0.162 & 32.122 & 1 & 0.000 & 2.507 & 1.824 & 3.445 \\
\hline & Age & 0.014 & 0.005 & 6.251 & 1 & 0.012 & 1.014 & 1.003 & 1.025 \\
\hline & Constant & 0.822 & 0.429 & 3.663 & 1 & 0.056 & 2.275 & & \\
\hline Model II: physical & AAl (scores $\geq 21$ ) & -0.108 & 0.418 & 0.066 & 1 & 0.797 & 0.898 & 0.395 & 2.038 \\
\hline exercise (men) & SCS (scores <27) & 0.377 & 0.318 & 1.409 & 1 & 0.235 & 1.458 & 0.782 & 2.719 \\
\hline \multirow[t]{3}{*}{$N=564$} & IPEDs & 1.427 & 0.328 & 18.950 & 1 & 0.000 & 4.165 & 2.191 & 7.917 \\
\hline & Age & 0.025 & 0.010 & 6.348 & 1 & 0.012 & 1.026 & 1.006 & 1.046 \\
\hline & Constant & -0.142 & 0.865 & 0.027 & 1 & 0.870 & 0.868 & & \\
\hline Model III: physical & AAl (scores $\geq 21$ ) & -0.315 & 0.182 & 2.988 & 1 & 0.084 & 0.730 & 0.511 & 1.043 \\
\hline exercise (women) & SCS (scores <27) & 0.183 & 0.174 & 1.109 & 1 & 0.292 & 1.201 & 0.854 & 1.688 \\
\hline \multirow[t]{3}{*}{$N=1,421$} & IPEDs & 0.720 & 0.188 & 14.641 & 1 & 0.000 & 2.054 & 1.421 & 2.969 \\
\hline & Age & 0.008 & 0.007 & 1.583 & 1 & 0.208 & 1.008 & 0.995 & 1.022 \\
\hline & Constant & 1.145 & 0.502 & 5.197 & 1 & 0.023 & 3.141 & & \\
\hline
\end{tabular}

Note: Physical exercise (0, "no practice"; 1, "practice"); IPEDs (0, "not used"; 1, "used"); AAl (0, scores <21; 1, scores $\geq 21)$, SCS (0, scores <27; 1, scores $\geq 27)$.

AAI, Appearance Anxiety Inventory; IPEDs, image- and performance-enhancing drug; SCS, Self-Compassion Scale.

participants, IPEDs use was also a significant predictor of exercising $(\mathrm{OR}=2.054,95 \%$ CI 1.421-2.969, $p<0.001)$. However, unlike male participants, age was not a significant predictor of physical exercise among female respondents. Appearance anxiety and self-compassion were not significant predictors of physical exercise among both male and female participants (Table 6).

The logistic regression on IPEDs consumption (classified as 0 , "not used," or 1, "used," according to the question, "Have you taken supplements/products to reach your fitness goal/physical appearance during self-isolation?") included problematic exercise $(0$, scores $<24 ; 1$, scores $\geq 24)$, AAI scores $(0,<21$; $1, \geq 21)$, SCS scores $(0,<27 ; 1, \geq 27)$, and age (Table 7$)$. The results showed that the strongest predictor of IPEDs use was problematic exercise $(\mathrm{OR}=2.726,95 \%$ CI 1.843-4.030; $p<$ $0.001)$, followed by appearance anxiety $(\mathrm{OR}=1.443,95 \% \mathrm{CI}$ $1.125-1.850, p=0.004)$. Thus, the probability of using IPEDs was almost triple for those scoring 24 or above the cutoff point of 24 on the EAI, and almost one and a half times greater for those who scored on or above the cutoff point of 21 on the AAI, than for those who scored below the cutoff points. Like in the previous regression, self-compassion was statistically non-significant. However, unlike in the previous regression, age was also a non-significant factor here.

When only male participants were considered, the results were similar to those obtained for the whole sample. Problematic exercise was the strongest predictor of IPEDs use $(\mathrm{OR}=2.227$, 95\% CI 1.215-4.084, $p=0.010$ ), followed by appearance anxiety $(\mathrm{OR}=1.912,95 \% \mathrm{CI} 1.146-3.189, p=0.013)$, and both variables were positively associated with IPEDs use (Table 7). This suggests that male participants who scored above the cutoff points (in both instruments) had about double the probability to use IPEDs than male participants who scored below the cutoff points. When only female respondents were considered, again, the strongest predictor of IPEDs use was problematic exercise $(\mathrm{OR}=3.003,95 \%$ CI 1.781-5.063, $p<0.001)$, followed by appearance anxiety $(\mathrm{OR}=1.511 ; 95 \% \mathrm{CI} 1.122-2.035, p=0.007)$, and both variables were positively associated with IPEDs use as well (Table 7). Additionally, age was significant, though only for female participants $(\mathrm{OR}=1.013$; 95\% CI 1.003-1.023; $p$ $=0.014)$. This indicates that problematic exercise was a strong predictor among female respondents, increasing by three times their probability of using IPEDs. This probability also increased with appearance anxiety and with age, though to a lesser extent (Table 7).

\section{Predictors of Change in Physical Exercise, in the Use of Image and Performance-Enhancing Drugs (IPEDs), and in Mental Health State During the Self-Isolation Period}

To assess changes during the self-isolation period, logistic regressions were conducted on three questions. One question assessed changes in physical exercise: Whether participants had a significant change in their fitness routine during this selfisolation period (0, "no"; 1 , “yes"). Another assessed changes in their use of IPEDs (0, "never used"; 1, "never used, but started during isolation"). The third assessed changes in their mental health state, and only participants who had responded "yes" to the question on whether they had a mental health diagnosis were included: Whether this self-isolation period worsened their 
TABLE 7 | Use of IPEDs logistic regression model (total and by gender).

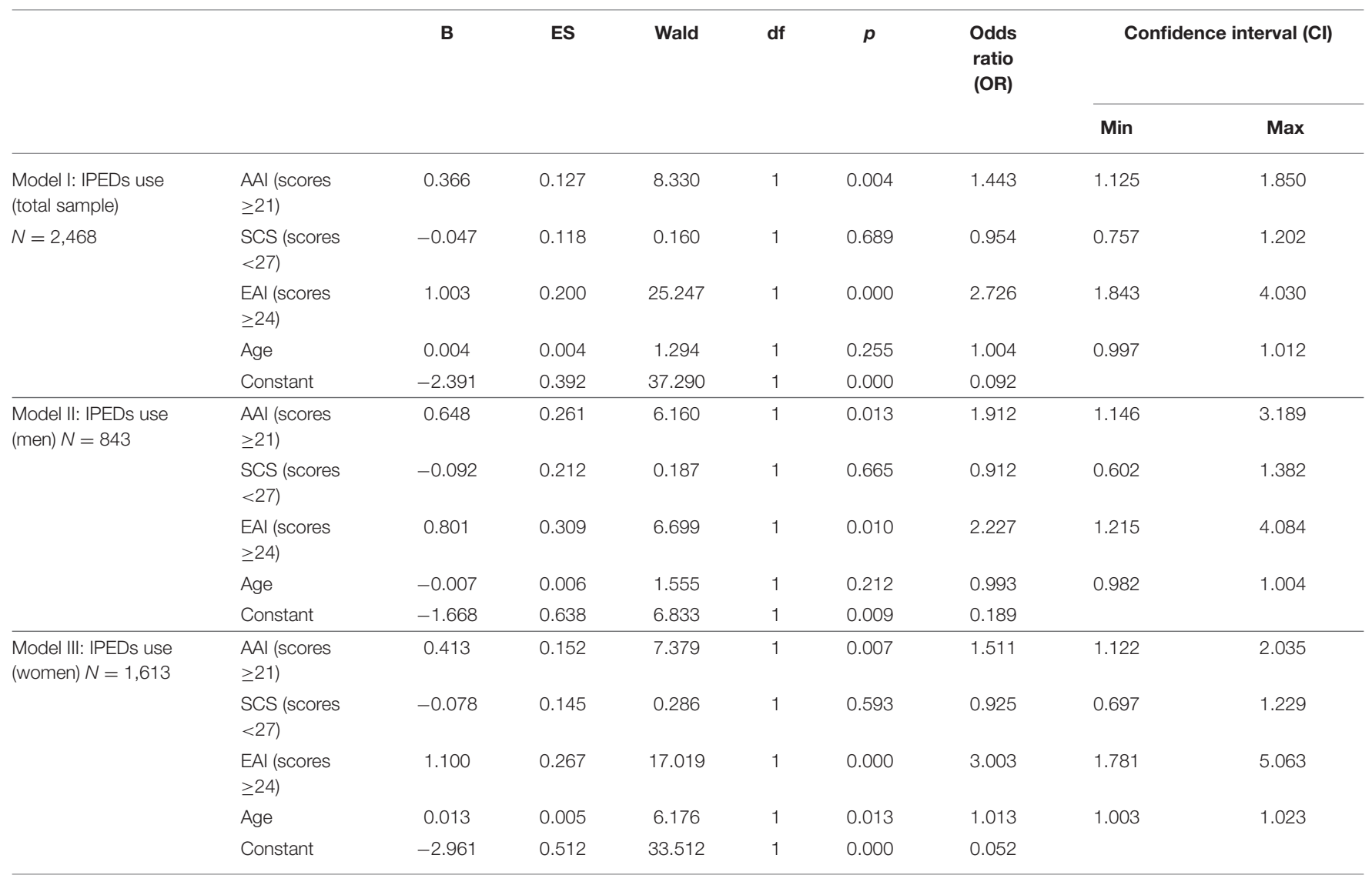

IPEDs use (0, not used; 1, used); problematic exercise (0, scores <24; 1 , scores $\geq 24)$; AAI (0, scores <21; 1 , scores $\geq 21)$; SCS (0, scores <27; 1 , scores $\geq 27)$.

AAI, Appearance Anxiety Inventory; IPEDs, image- and performance-enhancing drug; SCS, Self-Compassion Scale.

psychological discomfort (0, "no"; 1 , "yes"). The results of the regressions are presented in Table 8, respectively, on (1) change in physical exercise, (2) change in the use of IPEDs, and (3) change in mental health. The same predictors as before were included in the regression models. To inspect whether changes in physical exercise, use of IPEDs, and mental health were associated with being a key worker, the latter aspect was additionally included in the models ( 0 , "non-key worker"; 1 , "key worker").

Significant aspects associated with the change in physical exercise were IPEDs consumption (OR $=1.327,95 \% \mathrm{CI} 1.070$ $1.645, p=0.010)$ and being a key worker $(\mathrm{OR}=0.725,95 \% \mathrm{CI}$ $0.592-0.888, p=0.002$ ). This means that changes in practicing exercise were more likely when participants used IPEDs and were non-key workers.

The only predictor of change in IPEDs consumption was scoring 24 or above the cutoff of 24 on the EAI (OR $=2.272,95 \%$ CI $1.121-4.606, p=0.006$ ). This was a strong predictor, reflecting the idea that initiating IPEDs use during self-isolation was about two times more likely when participants scored above the cutoff point for problematic exercise.

Change in mental health was significantly and positively associated with anxiety about appearance (OR $=1.912,95 \%$ CI 1.203-3.039, $p=0.002$ ) and negatively associated with selfcompassion $(\mathrm{OR}=0.510,95 \%$ CI $0.334-0.779, p=0.002)$.
This means that, all else held constant, discomfort during the confinement period among participants with mental health history was more likely to worsen with increased anxiety about appearance and decreased self-compassion.

\section{DISCUSSION}

This study sought mainly to (1) characterize the practice of physical exercise and the consumption of IPEDs in a sample of the general population from seven countries worldwide during the lockdown and other restrictive measures, (2) analyze the potential associations of these behaviors with appearance anxiety (and the risk of BDD) and with self-compassion as a possible buffer of negative effects, and (3) analyze changes in those behaviors and in psychological discomfort during the lockdown and associated factors.

Scores of 24 or above such a cutoff score on the EAI are indicative of problematic exercising and are suggestive of exposure to the adverse effects of exercise, namely, injuries [e.g., $(24,73)]$. Excessive exercise also negatively impacting wellbeing and becoming harmful $(28,29)$. Although studies in this area are recent and scarce, the percentage of respondents at risk of problematic exercising in our sample (4.3\%) was large, 
TABLE 8 | Logistic regression on change in physical exercise, in IPEDs use, and in mental health.

\begin{tabular}{|c|c|c|c|c|c|c|c|c|c|}
\hline & & \multirow[t]{2}{*}{ B } & \multirow[t]{2}{*}{ ES } & \multirow[t]{2}{*}{ Wald } & \multirow[t]{2}{*}{ df } & \multirow[t]{2}{*}{$P$} & \multirow{2}{*}{$\begin{array}{l}\text { Odds } \\
\text { ratio (OR) }\end{array}$} & \multicolumn{2}{|c|}{ Confidence interval (Cl) } \\
\hline & & & & & & & & Min & Max \\
\hline $\begin{array}{l}\text { Model I: Change in physical exercise } \\
\text { Have you had a significant change in }\end{array}$ & $\begin{array}{l}\text { AAl (scores } \\
\geq 21 \text { ) }\end{array}$ & 0.234 & 0.153 & 2.355 & 1 & 0.125 & 1.264 & 0.937 & 1.704 \\
\hline $\begin{array}{l}\text { your fitness routine during this } \\
\text { self-isolation period? 0, "no"; } 1 \text {, "yes" }\end{array}$ & $\begin{array}{l}\text { SCS (scores } \\
<27 \text { ) }\end{array}$ & -0.045 & 0.132 & 0.116 & 1 & 0.733 & 0.956 & 0.738 & 1.239 \\
\hline \multirow[t]{5}{*}{$N=2,464$} & IPEDs & 0.283 & 0.110 & 6.633 & 1 & 0.010 & 1.327 & 1.070 & 1.645 \\
\hline & Gender & -0.114 & 0.105 & 1.194 & 1 & 0.275 & 0.892 & 0.727 & 1.095 \\
\hline & Age & 0.002 & 0.004 & 0.227 & 1 & 0.634 & 1.002 & 0.994 & 1.011 \\
\hline & $\begin{array}{l}\text { Key worker } \\
\text { (No/Yes) }\end{array}$ & -0.321 & 0.103 & 9.678 & 1 & 0.002 & 0.725 & 0.592 & 0.888 \\
\hline & Constant & 1.189 & 0.410 & 8.408 & 1 & 0.004 & 3.283 & & \\
\hline $\begin{array}{l}\text { Model II: Change in IPEDs use } \\
\text { Have you taken more }\end{array}$ & $\begin{array}{l}\text { AAl (scores } \\
\geq 21 \text { ) }\end{array}$ & 0.060 & 0.252 & 0.057 & 1 & 0.812 & 1.062 & 0.648 & 1.739 \\
\hline $\begin{array}{l}\text { supplements/products to reach your } \\
\text { fitness goal/physical appearance }\end{array}$ & $\begin{array}{l}\text { SCS (scores } \\
<27)\end{array}$ & -0.204 & 0.218 & 0.877 & 1 & 0.349 & 0.815 & 0.532 & 1.250 \\
\hline $\begin{array}{l}\text { during self-isolation } 0 \text {, "never used"; } \\
1 \text {, "never used, but started during }\end{array}$ & $\begin{array}{l}\text { EAl (scores } \\
\geq 24 \text { ) }\end{array}$ & 0.821 & 0.360 & 5.184 & 1 & 0.023 & 2.272 & 1.121 & 4.606 \\
\hline isolation" & Gender & -0.198 & 0.179 & 1.220 & 1 & 0.269 & 0.820 & 0.577 & 1.166 \\
\hline \multirow[t]{3}{*}{$N=1,917$} & Age & 0.000 & 0.007 & 0.004 & 1 & 0.951 & 1.000 & 0.985 & 1.014 \\
\hline & $\begin{array}{l}\text { Key worker } \\
\text { (No/Yes) }\end{array}$ & -0.068 & 0.186 & 0.134 & 1 & 0.714 & 0.934 & 0.648 & 1.346 \\
\hline & Constant & -2.613 & 0.789 & 10.975 & 1 & 0.001 & 0.073 & & \\
\hline $\begin{array}{l}\text { Model III: Change in mental health } \\
\text { Has this self-isolation period }\end{array}$ & $\begin{array}{l}\text { AAl (scores } \\
\geq 21 \text { ) }\end{array}$ & 0.648 & 0.236 & 7.514 & 1 & 0.006 & 1.912 & 1.203 & 3.039 \\
\hline $\begin{array}{l}\text { worsened your psychological } \\
\text { discomfort 0, "no"; 1, "yes" }\end{array}$ & $\begin{array}{l}\text { SCS (scores } \\
<27)\end{array}$ & -0.674 & 0.216 & 9.722 & 1 & 0.002 & 0.510 & 0.334 & 0.779 \\
\hline \multirow[t]{6}{*}{$N=438$} & $\begin{array}{l}\text { EAl (scores } \\
\geq 24)\end{array}$ & 0.271 & 0.413 & 0.428 & 1 & 0.513 & 1.311 & 0.583 & 2.947 \\
\hline & IPEDs & 0.0072 & 0.224 & 0.104 & 1 & 0.748 & 1.075 & 0.693 & 1.665 \\
\hline & Gender & 0.277 & 0.262 & 1.119 & 1 & 0.290 & 1.319 & 0.790 & 2.203 \\
\hline & Age & -0.005 & 0.010 & 0.209 & 1 & 0.648 & 0.995 & 0.975 & 1.016 \\
\hline & $\begin{array}{l}\text { Key worker } \\
\text { (No/Yes) }\end{array}$ & -0.018 & 0.250 & 0.005 & 1 & 0.943 & 0.982 & 0.602 & 1.604 \\
\hline & Constant & -0.992 & 0.905 & 1.202 & 1 & 0.273 & 0.371 & & \\
\hline
\end{tabular}

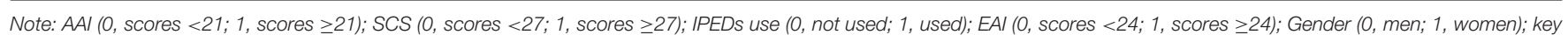
worker (0, "non-key worker"; 1, "key worker").

AAI, Appearance Anxiety Inventory; IPEDs, image- and performance-enhancing drug; SCS, Self-Compassion Scale.

comparing with the proportions found in other studies also conduced within community samples but prior to the COVID19 pandemic [e.g., reported percentages range between 0.3 and $0.5 \%$ (24)]. This percentage was smaller than the proportion found among gym users before the COVID-19 pandemic $(11.7 \%)$ (23) or among the exercise practitioners of Spanish-speaking countries (15.2\%) in the recent study that was carried out during the COVID-19 lockdown period-in April of 2020 (65). Our results further showed that more male than female respondents displayed a risk of problematic exercising, which is consistent with previous studies [e.g., $(23,42-44)]$.

The multicultural nature of our study made it possible to identify a significant association between problematic exercise and country. The UK registered the largest percentage of participants at risk for problematic exercising (11.0\%). This was more than double the value found in Spain (5.4\%) and generally more than triple the values registered in the remaining countries that ranged from $2.4 \%$ (in Lithuania) to $3.7 \%$ (in Hungary). The percentage in the UK was similar to that previously reported among gym users (23); this may be explained by the fact that the UK also had a large percentage of participants who practice exercise (97.1\%; Table 1), greater than five of the other countries. However, Hungary had a larger number of participants who practice exercise (98.2\%; Table 1), yet showed a much smaller percentage of respondents at risk for problematic exercising (3.7\%) than the UK $(11.0 \%)$ or Spain $(5.4 \%)$. The remaining three countries (Portugal, Italy, and Lithuania) displayed the largest percentages of participants who did not practice exercise 
with scores ranging between $15 \%$ and $20 \%$ (Table 1), and their respective percentages of participants at risk for problematic exercising (ranging between 2.4\% for Lithuania and 3.1\% for Italy) were closer to Japan's than to their European counterparts (i.e., the UK and Spain). It is possible that cross-cultural differences play a role in determining the rationale behind the practice of physical exercise (74). Such a hypothesis is supported by the fact that even within fitness settings, where risk of problematic exercising is higher, a larger percentage of problematic exercisers was found in the UK (16.1\%) compared to that in Hungary $(9.3 \%)$ or Italy $(7.9 \%)$ in a study that was carried out just before the COVID-19 pandemic (23). In Spain, high scores of problematic exercising were found in the pre-COVID19 period among university students (6\%), although a different measurement was used [Exercise Dependence Scale (EDS-R)] (75). Another study found an even greater percentage (14.9\%) of students at risk of addiction on the EAI (76). The prevalence of problematic exercising in the general Spanish population in other studies was about $3 \%(74)$.

Although the concept of EA is not consensual, the comparatively high number of participants displaying such risk among the general population during the COVID-19 lockdown period suggests that results emerging from our study should be taken into consideration and inform future restrictive measures, while emphasizing group vulnerabilities in crosscultural differences.

The same argument is valid for IPEDs consumption. Overall, $28 \%$ of the respondents across the general population used these products during the lockdown. Among these, $6.4 \%$ began a new use of IPEDs, while only $1.5 \%$ reduced their use. This might suggest that the use of IPEDs is a coping strategy to deal with the challenges posed by the COVID-19 pandemic, including distress related to body image experienced during quarantine. As previously suggested (50), the social pressure to achieve a "perfect body," combined with the easy online access to IPEDs supported by aggressive and misleading advertisement strategies, promising fast solutions, could be a possible explanation for the observed growing phenomenon during the lockdown. Further, participants in our study mostly boosted their image and performance with the consumption of legal compounds (e.g., medicine, supplements), which in $43.2 \%$ of the cases were acquired from the Internet possibly with no professional advice and supervision as previously noticed (29).

Male respondents reported using IPEDs significantly more than female respondents, and their intake significantly differed across countries, with Hungary and Japan displaying the largest consumption (Table 3). In the case of Hungary, this might have been influenced by the fact that the sample had the lowest representation of students (9\%) and, consequently, had the highest mean age, which could be a contributing factor to such difference with other countries. Further, Hungarians recorded the smallest percentage of participants who did not exercise (1.8\%) and, compared to the others, their sample was composed of the highest proportion of both runners (27.9\%) and swimmers (28.8\%). Based on such characteristics, it appears that either by chance, or due to self-selection, the Hungarian population was the most physically active population within our sample, thus explaining the results concerning the IPEDs use.

Considering that, so far, the widespread consumption of IPEDs has been associated only with professional fitness settings (23), the results from our study across the general population are surprisingly high compared with those emerged from previous studies (23). Interestingly, the countries registering the greatest percentages of IPEDs consumers were also those presenting the greatest percentages of participants practicing exercise with the exception of Lithuania (Table 1). In this latter case, the smallest percentage of participants at risk of EA across the entire sample was also reported (Table 2). Overall, our results are indicative that IPEDs are also used outside the context of problematic or excessive exercise and, especially in the case of Lithuania, outside the context of the practice of exercise. Nevertheless, excessive levels of exercise have been suggested to be associated with a greater tendency for using IPEDs (23), indicating that careful attention should be given to excessive supplement use among individuals engaging in problematic levels of exercise practice.

Finally, those most affected by appearance anxiety were in Italy (18.1\%) and Japan (16.9\%), mainly female participants. Although the literature is limited, a previous study indicated that Italian women compared with South Asians and British women seemed to consider themselves more "overweight" and "fairly unhappy with the way they look" (77). Another study also indicated higher levels of thin-ideal internalization and peer and media pressure across Italian women (78). Such an attitude might have been magnified by stricter national lockdown at the time of the data collection compared to other countries. Italy was in fact the first country in the European Union to be affected by the pandemic (79), causing an unprecedented negative impact on the mental well-being and significant emotional distress that could have reinforced the high scores on the AAI in our study.

At the same time, young Japanese females have been shown to have a stronger desire to get slender bodies, manifested by the feelings of ideal body images in individuals with lower body mass index (BMI) compared to Europeans (80). This difference in "ideal body image" among the countries could explain the higher rate of Japanese population with high AAI scores.

Our regression models showed a strong relation between physical exercise and IPEDs use. Using IPEDs significantly predicted the probability of practicing exercise in the whole sample, particularly among males (for whom the probability increased by four and a half times). An unexpected result was that self-compassion was non-significantly associated with practicing exercise.

Our regressions on the use of IPEDs additionally showed that the risk of addiction to exercise (i.e., scores $\geq 24$ on the EAI) significantly predicted IPEDs use across the three considered groups and note in the three groups considered (whole sample and male and female participants), doubling or tripling the probability of consumption. As expected, high anxiety about physical appearance also significantly increased the probability of using IPEDs in the three groups (by at least one and a half to two times more), underscoring the role of psychological discomfort on the consumption of these products. However, again, selfcompassion was non-significantly associated with using IPEDs. 
In sum, consumption of IPEDs predicted the practice of physical exercise, thus the risk of problematic exercising predicted IPEDs consumption. These results support those in a recent study reporting, for the first time, the association between the consumption of IPEDs and problematic exercising (23). High appearance anxiety predicted more consumption of IPEDs but not the practice of exercise. Vulnerable groups are thus particularly likely to use IPEDs. This is consistent with the easy access to IPEDs and the notion that advertising strategies promising easy and quick results from their consumption might be transforming such consumption into a preferred strategy compared to exercising, particularly during the period in which its practice has become more difficult due to restrictive measures and possible lack of space at home.

Regarding changes in habits during the COVID-19 lockdown period, a small proportion of the sample participants reported having started using IPEDs during isolation (6.4\%). Changes in fitness routines (though not in the use of IPEDs) were significantly less likely to occur if participants were key workers rather than non-key workers. Seemingly, key workers were able to maintain the various domains of their lives functioning during the lockdown. The fact that IPEDs use was one aspect that significantly contributed to the changes in exercise practice and that the risk of problematic exercising was the only aspect that significantly contributed to the increase in the use of IPEDs during the quarantine period underlines the potential influence that the particular circumstances of restriction might have in exacerbating these phenomena and the association between them.

Several participants with mental health conditions considered that their psychological discomfort has worsened during isolation (47.9\%) (Table 1). Both increased symptom domains associated with BDD and decreased self-compassion contributed significantly to this change. Such changes in mental health, related to body image (dis)satisfaction and with difficulties in emotional self-regulation, could contribute to alter behaviors and habits that, although intended to minimize or supress the dissatisfaction, could become harmful to vulnerable groups, affecting several life dimensions. In this study, however, we found no evidence for the occurrence of these altered behaviors in the sequence of worsening psychological discomfort because the association of these changes in mental health with both the risk of problematic exercising and the use of IPEDs was statistically nonsignificant.

Regarding age, there was a positive association between the age of the participants and exercising in the total sample but, also between the age of the participants and consumption of IPEDs among female respondents. According to Szabo $(28,49)$, adherence to a healthier lifestyle should increase with age, and it is necessary to understand the effect of this variable on exercising and the type of IPEDs used to better understand this association.

Overall, our culturally enriched investigation was a timely contribution to a better understanding of the risks, and not only the benefits, associated with exercise and the IPEDs consumption as coping strategies during a period of highly restrictive measures of freedom and social contact due to the COVID-19 pandemic. Despite the adversities faced by all of us, we were able to rapidly capture a large set of data from a cross-cultural sample in seven countries worldwide right at the beginning of the pandemic, which reflected significant changes in variables of interest. However, our effort is not exempt from limitations. First, the study is based on a non-stratified sample and on voluntary participation, which might introduce selection bias because the representativeness of the population is not ensured. Second, the snowball recruitment process and the online nature of data collection might help explain some of the high prevalences obtained. Nevertheless, the studies on this topic were based on similarly voluntary participation, making comparisons possible. Third, the study relies on self-reported measures, thus it is subject to the biases that characterize this modality of inquiry, namely, regarding consumption of IPEDs, which was not validated through any biological testing. Fourth, clinical interpretations of the results require caution because, for some instruments (notably the AAI), a statistical cutoff point was used to identify high anxiety about physical appearance and the symptom domains associated with BDD, instead of a clinical cutoff point, which is not available. Fifth, information on the individual's history of exercise and consumption of IPEDs is lacking, to support a better understanding of the excessive and the problematic nature of such behaviors, including their frequency and duration. Sixth, the study design does not allow causal inferences, although conclusions on the relative associations between the variables were possible.

We are confident that future studies can further illuminate our findings by addressing and overcoming such limitations, which we were unable to control during this narrow window of opportunity. Additional evidence should be collected on the so far poorly understood relationships between physical exercise and the use of IPEDs and the role of precipitating and of protecting factors (i.e., problematic exercising and appearance anxiety as precipitating factors and self-compassion as a protecting factor) that very recent investigations, including this study, have started to show. The inclusion of psychiatric interviews and/or objective tests would also contribute to further validate the self-reported responses of our online sample. Having identified the most at risk population, more targeted and effective prevention strategies could be more easily be implemented, even more importantly during periods of personal confinement. Some reinforcement programs on addiction health care have been launched during the pandemic (81). They address behaviors other than exercise or the use of enhancement drugs, but similar initiatives could be created in the future, targeting the latter aspects as well. It is worth noting that those affected by problematic exercise and IPEDs use under normal conditions rarely come to the attention of health professionals in part because of the "normalization" of their behavior in society and the fact that they do not consider themselves "drug users" in a traditional sense. If care is sought, primary care doctors, as opposed to psychiatrists or psychologists, are consulted. By identifying those who are most affected, including frequent exercisers, public health and clinical interventions can be developed and more adequately help them to adjust better, thereby relieving personal distress, improving health and well-being, restoring family and occupational and social functioning, and ultimately supporting the economic growth of our countries. 


\section{DATA AVAILABILITY STATEMENT}

The raw data supporting the conclusions of this article will be made available by the authors, without undue reservation.

\section{ETHICS STATEMENT}

The studies involving human participants were reviewed and approved by Human Sciences Ethics Committee at the University of Hertfordshire (HSK/SF/UH/00104). The patients/participants provided their written informed consent to participate in this study.

\section{AUTHOR CONTRIBUTIONS}

Conceptualization: OC, PS, GM, and NF. Methodology: OC, PS, GM, NF, AD, and IC. Formal analysis: JB and AD. Investigation and data collection: ID, KÁ, AD, PS, RM, MG-M, AV, EA-A, RSL, JB, IG-B, AP, ZD, AS, HF, MS, and KK. Resources: AD, OC, and NF. Data curation: OC, AD, JB, RM, and ZD. Writing-original draft preparation: AD. Writing-review and editing: IC, RM, JB, FB, and KI. Visualization: AD and IC. Supervision: OC, AD,

\section{REFERENCES}

1. World Health Organization. WHO Director-General's Opening Remarks at the Media Briefing on COVID-19 - 11 March 2020. (2020). Available online at: https://www.who.int/dg/speeches/detail/who-director-general-sopening-remarks-at-the-media-briefing-on-covid-19 (accessed June 29, 2020).

2. $\mathrm{Xu} \mathrm{Z}$, Li S, Tian S, Li H, Kong LQ. Full spectrum of COVID-19 severity still being depicted. Lancet. (2020) 395:9478. doi: 10.1016/S0140-6736(20)30308-1

3. Cothran TP, Kellman S, Singh S, Beck JS, Powell KJ, Bolton CJ, et al. A brewing storm: the neuropsychological sequelae of hyperinflammation due to COVID-19. Brain Behav Immun. (2020) 88:957-8. doi: 10.1016/j.bbi.2020. 06.008

4. Torales J, O'Higgins M, Castaldelli-Maia JM, Ventriglio A. The outbreak of COVID-19 coronavirus and its impact on global mental health. Int J Soc Psychiatry. (2020) 66:317-20. doi: 10.1177/002076402091 5212

5. Ferguson N, Laydon D, Nedjati-Gilani G, Imai N, Ainslie K, Baguelin M, et al. Report 9: impact of non-pharmaceutical interventions (NPIs) to reduce COVID-19 mortality and healthcare demand. Imperial College London. (2020) 10:77482. doi: 10.25561/77482

6. Mendes-Santos C, Andersson G, Weiderpass E, Santana R. Mitigating COVID-19 impact on the portuguese population mental health: the opportunity that lies in digital mental health. Front Public Health. (2020) 8:e553345. doi: 10.3389/fpubh.2020.553345

7. Wise T, Zbozinek TD, Michelini G, Hagan CC, Mobbs D. Changes in risk perception and self-reported protective behaviour during the first week of the COVID-19 pandemic in the United States. R Soc Open Sci. (2020) 7:200742. doi: $10.1098 /$ rsos. 200742

8. Santana R, Rocha J, Soares P, Sousa J. Os Momentos das Politicas de Saúde no Combate ao COVID-19, Barómetro COVID-19 [The moments of health policies to tackle COVID-19, Barometer COVID-19]. Lisbon: Escola Nacional de Saúde Pública-Universidade Nova de Lisboa (2020).

9. Ammar A, Trabelsi K, Brach M, Chtourou H, Boukhris O, Masmoudi L, et al. Effects of home confinement on mental health and lifestyle behaviours during the COVID-19 outbreak: Insight from the "ECLBCOVID19” multi countries survey. medRxiv. (2020) 2020.05.04.20091017. doi: 10.1101/2020.05.04.20091017 and IC. Project administration: OC. Funding acquisition: NF, $\mathrm{OC}$, and $\mathrm{AD}$. All authors have read and agreed to the published version of the manuscript.

\section{FUNDING}

This article/publication is based upon work from COST Action CA16207 European Network for Problematic Usage of the Internet, supported by COST (European Cooperation in Science and Technology). www.cost.eu. This research was supported by Fundação para a Ciência e Tecnologia (FCT) through R\&D Units funding (UIDB/05210/2020).

\section{ACKNOWLEDGMENTS}

The authors wish to thank Dorotea Cicconcelli, Valentina Giorgetti, Antonino Todaro, Attilio Negri, Viviane Beretta, Elisabeth Prevete, Katinka van de Ven, among other frontline professionals, and other contributors within the COST Action Project, who supported the dissemination of the study during an extremely busy and challenging time in human history due to the pandemic.

10. Prime $\mathrm{H}$, Wade $\mathrm{M}$, Browne DT. Risk and resilience in family wellbeing during the COVID-19 pandemic. Am Psychol. (2020) 75:63143. doi: $10.1037 / \mathrm{amp} 0000660$

11. Dores AR, Geraldo A, Carvalho IP, Barbosa F. The use of new digital information and communication technologies in psychological counseling during the COVID-19 pandemic. Int J Environ Res Public Health. (2020) 17:7663. doi: 10.3390/ijerph17207663

12. Bluedorn J, Gopinath G, Sandri D. An Early View of the Economic Impact of the Pandemic in 5 Charts. IMFBlog-Insights \& Analysis on Economics \& Finance (2020).

13. Maital S, Barzani E. The global economic impact of COVID-19: A summary of research. Samuel Neaman Institute for National Policy Research. Haifa (2020).

14. Stiglitz JE, Shiller RJ, Gopinath G, Reinhart CM, Posen A, Prasad E, et al. How the economy will look after the coronavirus pandemic. Foreign Policy. (2020) 15. [Epub ahead of print].

15. Mazza M, Marano G, Antonazzo B, Cavarretta E, Di Nicola M, Janiri L, et al. What about heart and mind in the covid-19 era? Minerva Cardioangiol. (2020). doi: 10.23736/S0026-4725.20.05309-8. [Epub ahead of print].

16. Alzueta E, Perrin P, Baker FC, Caffarra S, Ramos-Usuga D, Yuksel D, et al. How the COVID-19 pandemic has changed our lives: A study of psychological correlates across 59 countries. J Clin Psychol. (2020) 77:55670. doi: $10.1002 /$ jclp. 23082

17. Brooks SK, Webster RK, Smith LE, Woodland L, Wessely S, Greenberg N, et al. The psychological impact of quarantine and how to reduce it: rapid review of the evidence. Lancet. (2020) 395:912-20. doi: 10.1016/S0140-6736(20)30460-8

18. Hossain MM, Sultana A, Purohit N. Mental health outcomes of quarantine and isolation for infection prevention: a systematic umbrella review of the global evidence. Epidemiol Health. (2020) 42:e2020038-0. doi: 10.4178/epih.e2020038

19. Jeong H, Yim HW, Song Y-J, Ki M, Min J-A, Cho J, et al. Mental health status of people isolated due to Middle East Respiratory Syndrome. Epidemiol Health. (2016) 38:e2016048. doi: 10.4178/epih.e2016048

20. Webster RK, Brooks SK, Smith LE, Woodland L, Wessely S, Rubin GJ. How to improve adherence with quarantine: rapid review of the evidence. Public Health. (2020) 182:163-9. doi: 10.1016/j.puhe.2020. 03.007

21. Horesh D, Brown AD. Traumatic stress in the age of COVID-19: a call to close critical gaps and adapt to new realities. Psychol Trauma. (2020) 12:331-5. doi: $10.1037 /$ tra0000592 
22. Holmes EA, O'Connor RC, Perry VH, Tracey I, Wessely S, Arseneault L, et al. Multidisciplinary research priorities for the COVID-19 pandemic: a call for action for mental health science. Lancet Psychiatry. (2020) 7:54760. doi: 10.1016/S2215-0366(20)30168-1

23. Corazza O, Simonato P, Demetrovics Z, Mooney R, van de Ven K, Roman-Urrestarazu A, et al. The emergence of Exercise Addiction, Body Dysmorphic Disorder, and other image-related psychopathological correlates in fitness settings: A cross sectional study. PLoS ONE. (2019) 14:e0213060. doi: 10.1371/journal.pone.0213060

24. Glasser W. Positive Addiction. New York, NY: Harper and Row (1976).

25. Griffiths MD. Behavioural addictions: an issue for everybody? J Workplace Learn. (1996) 8:19-25.

26. Griffiths MD. Exercise addiction: a case study. Add Res. (1997) 5:1618. doi: 10.3109/16066359709005257

27. Griffiths MD. Gambling and Gaming Addictions in Adolescence. British Psychological Society (2002). Leicester: British Psychological Society/Blackwells.

28. Szabo A. The impact of exercise deprivation on well-being of habitual exercises. Aust J Sci Med Sport. (1995) 27:68-75.

29. De Luca I, Simonato P, Mooney R, Bersani G, Corazza O. Can exercise be an addiction? The evolution of 'fitspiration' in society. Res Adv Psychiatry. (2017) $4: 27-34$.

30. Mooney R, Simonato P, Ruparelia R, Roman-Urrestarazu A, Martinotti G, Corazza $\mathrm{O}$. The use of supplements and performance and image enhancing drugs in fitness settings: an exploratory cross-sectional investigation in the United Kingdom. Human Psychopharmacol. (2017) 32. doi: 10.1002/hup.2619

31. Barry CT, Doucette H, Loflin DC, Rivera-Hudson N, Herrington LL. Let me take a selfie: associations between self-photography, narcissism, and selfesteem. Psychol Popular Media Cult. (2017) 6:48. doi: 10.1037/ppm0000089

32. Mabe AG, Forney KJ, Keel PK. Do you "like" my photo? Facebook use maintains eating disorder risk. Int J Eating Disord. (2014) 47:51623. doi: 10.1002/eat.22254

33. Meier EP, Gray J. Facebook photo activity associated with body image disturbance in adolescent girls. Cyberpsychol Behav Soc Network. (2014) 17:199-206. doi: 10.1089/cyber.2013.0305

34. Simpson CC, Mazzeo SE. Skinny is not enough: a content analysis of fitspiration on pinterest. Health Commun. (2017) 32:560-7. doi: 10.1080/10410236.2016.1140273

35. Giorgetti V, Cicconcelli D, De Luca I, Abdi S, Negri A, Bersani FS, et al. Fitspiration on social media: body-image and other psychopathological risks among young adults. (submitted).

36. Carrotte ER, Prichard I, Lim MSC. "Fitspiration" on social media: a content analysis of gendered images. J Med Internet Res. (2017) 19:e95. doi: 10.2196/jmir.6368

37. Raggatt M, Wright CJ, Carrotte E, Jenkinson R, Mulgrew K, Prichard I, et al. "I aspire to look and feel healthy like the posts convey": engagement with fitness inspiration on social media and perceptions of its influence on health and wellbeing. BMC Public Health. (2018) 18:1002. doi: 10.1186/s12889-018-5930-7

38. Cockerill IM, Riddington ME. Exercise dependence and associated disorders: a review. Counsel Psychol Q. (1996) 9:119-29. doi: 10.1080/09515079608256358

39. Brown RIF. Some contributions of the study of gambling to the study of other addictions. In: Eadington WR, Cornelius JA, editors. Gambling Behaviour and Problem Gambling. Reno, NV: Reno University of Nevada Press (1993). p. 241-72.

40. World Health Organization. International Classification of Diseases for Mortality and Morbidity Statistics. (2018). Available online at: https://icd.who. int/browse11/l-m/en (accessed May 10, 2020).

41. American Psychiatric Association. Diagnostic and Statistical Manual of Mental Disorders (5th ed.). Washington, DC: American Psychiatric Association (2013).

42. Edmunds J, Ntoumanis N, Duda JL. examining exercise dependence symptomatology from a self-determination perspective. J Health Psychol. (2006) 11:887-903. doi: 10.1177/1359105306069091

43. Hausenblas HA, Fallon EA. Relationship among body image, exercise behavior, and exercise dependence symptoms. Int J Eating Disord. (2002) 32:179-85. doi: 10.1002/eat.10071
44. Hausenblas HA, Downs DS. Exercise dependence: a systematic review. Psychol Sport Exercise. (2002) 3:89-123. doi: 10.1016/S1469-0292(00) 00015-7

45. Kjelsås E, Augestad L. Gender differences in competitive runners and their motive for physical activity. Euro J Psychiatry. (2003) 17:157-71.

46. Zmijewski CF, Howard MO. Exercise dependence and attitudes toward eating among young adults. Eating Behav. (2003) 4:181-95. doi: 10.1016/s1471-0153(03)00022-9

47. Costa S, Hausenblas HA, Oliva P, Cuzzocrea F, Larcan R. The role of age, gender, mood states and exercise frequency on exercise dependence. J Behav Add. (2013) 2:216-23. doi: 10.1556/JBA.2.2013.014

48. Sussman S, Lisha N, Griffiths M. Prevalence of the addictions: a problem of the majority or the minority? Eval Health Prof. (2011) 34:356. doi: 10.1177/0163278710380124

49. Szabo A. Physical activity as a source of psychological dysfunction. In: Biddle SJ, Fox KR, Boutcher SH, editors. Physical Activity and Psychological WellBeing. London: Routledge (2000). p. 130-53.

50. Bates G, McVeigh J. Image and Performance Enhancing Drugs. National IPED INFO Survey. (2015). Available online at: http://www.ipedinfo.co. uk/resources/downloads/2015\%20National\%20IPED\%20Info\%20Survey \%20report.pdf (accessed May 20, 2020).

51. Corazza O, Assi S, Simonato P, Corkery J, Bersani FS, Demetrovics Z, et al. Promoting innovation and excellence to face the rapid diffusion of novel psychoactive substances in the EU: the outcomes of the ReDNet project. Human Psychopharmacol. (2013) 28:317-23. doi: 10.1002/hup.2299

52. Corazza O, Bersani FS, Brunoro R, Valeriani G, Martinotti G, Schifano F. The diffusion of performance and image-enhancing drugs (PIEDs) on the internet: the abuse of the cognitive enhancer piracetam. Substance Use Misuse. (2014) 49:1849-56. doi: 10.3109/10826084.2014.912232

53. Kamber M, Mullis P-E. The worldwide fight against doping: from the beginning to the world anti-doping agency. Endocrinol Metab Clin North Am. (2010) 39:1-9. doi: 10.1016/j.ecl.2009.10.009

54. Molinero O, Márquez S. Use of nutritional supplements in sports: risks, knowledge, and behavioural-related factors. Nutr Hospital. (2009) 24:128-34.

55. Van Hout MC. SMART: an Internet study of users experiences of synthetic tanning. Perform Enhance Health. (2014) 3:314. doi: 10.1016/j.peh.2014.05.001

56. Beucke JC, Sepulcre J, Buhlmann U, Kathmann N, Moody T, Feusner JD. Degree connectivity in body dysmorphic disorder and relationships with obsessive and compulsive symptoms. Euro Neuropsychopharmacol. (2016) 26:1657-66. doi: 10.1016/j.euroneuro.2016.04.011

57. Ioannidis K, Hook RW, Grant JE, Czabanowska K, RomanUrrestarazu A, Chamberlain SR. Eating disorders with over-exercise: a cross-sectional analysis of the mediational role of problematic usage of the internet in young people. J Psychiatric Res. (2020) 132:215-22 doi: 10.1016/j.jpsychires.2020.11.004

58. Soler PT, Harada Ferreira C, da Silva Novaes JFH. Body dysmorphic disorder: characteristics, psychopathology, clinical associations, and influencing factors. In: Gaze DC, editor. Pathophysiology - Altered Physiological States. IntechOpen. (2018). doi: 10.5772/intechopen.76446

59. Bewley A. The neglected psychological aspects of skin disease. Brit Med J Publish Group. (2017) 358:j3208. doi: 10.1136/bmj.j3208

60. Castilho P, Gouveia JP. Auto-compaixão: estudo da validação da versão Portuguesa da escala da auto-compaixão e da sua relação com as experiências adversas na infância, a comparação social e a psicopatologia [Self-compassion: Validation of the Portuguese version of the Selfcompassion Scale and its relation with an adverse childhood experiences, social comparison and psychopathology]. Psychologica. (2011) 54:20330. doi: 10.14195/1647-8606_54_8

61. Costa J, Marôco J, Pinto-Gouveia J, Ferreira C, Castilho P. Validation of the psychometric properties of the self-compassion scale. Testing the factorial validity and factorial invariance of the measure among borderline personality disorder, anxiety disorder, eating disorder and general populations. Clin Psychol Psychother. (2016) 23:460-8. doi: 10.1002/cpp.1974

62. Cacioppo JT, Hawkley LC. Social isolation and health, with an emphasis on underlying mechanisms. Perspect Biol Med. (2003) 46(Suppl. 3):S39-52.

63. Hausenblas HA, Schreiber K, Smoliga JM. Addiction to exercise. BMJ. (2017) 357:j1745. doi: 10.1136/bmj.j1745 
64. Wang M, Baker JS, Quan W, Shen S, Fekete G, Gu Y. A preventive role of exercise across the coronavirus 2 (SARS-CoV-2) pandemic. Front Physiol. (2020) 11:572718. doi: 10.3389/fphys.2020.572718

65. de la Vega R, Almendros LJ, Barquín RR, Boros S, Demetrovics Z, Szabo A. Exercise addiction during the COVID-19 pandemic: an international study confirming the need for considering passion and perfectionism. Int J Ment Health Addict. (2020) 2020:1-12. doi: 10.1007/s11469-020-00433-7. [Epub ahead of print].

66. World Health Organization. Stay Physically Active During Self-Quarantine. Copenhagen: World Health Organization (2020).

67. Terry A, Szabo A, Griffiths MD. The exercise addiction inventory: a new brief screening tool. Add Res Theory. (2004) 12:489-99. doi: 10.1080/16066350310001637363

68. Griffiths M, Szabo A, Terry A. The exercise addiction inventory: a quick and easy screening tool for health practitioners. Brit J Sports Med. (2005) 39:e30. doi: 10.1136/bjsm.2004.017020

69. Griffiths MD. A "components" model of addiction within a biopsychosocial framework. J Subst Use. (2005) 10:191-7. doi: 10.1080/14659890500114359

70. Griffiths MD, Urbán R, Demetrovics Z, Lichtenstein MB, de la Vega R, Kun B,... Szabo, et al. A cross-cultural re-evaluation of the Exercise Addiction Inventory (EAI) in five countries. Sports Med Open. (2015) 1:5. doi: 10.1186/s40798-014-0005-5

71. Veale D, Eshkevari E, Kanakam N, Ellison N, Costa A, Werner T. The appearance anxiety inventory: validation of a process measure in the treatment of body dysmorphic disorder. Behav Cognit Psychother. (2014) 42:605-16. doi: 10.1017/s1352465813000556

72. Neff KD. The development and validation of a scale to measure selfcompassion. Self Identity. (2003) 2:223-50. doi: 10.1080/15298860309027

73. Freimuth M, Moniz S, Kim SR. Clarifying exercise addiction: differential diagnosis, co-occurring disorders, and phases of addiction. Int J Environ Res Public Health. (2011) 8:4069-81. doi: 10.3390/ijerph8104069

74. Márquez S, de la Vega S. Exercise addiction: an emerging conduct disorder. Hospital Nutr. (2015) 31:2384-91. doi: 10.3305/nh.2015.31.6.8934

75. Reche García C, Martínez-Rodríguez A, Ortín FJ. Dependence on physical exercise and mood indicators in university athletes. Notebooks Sports Psychol. (2015) 15:21-26. doi: 10.4321 / S1578- 84232015000200003

76. Sicilia Á, Alías-García A, Ferriz R, Moreno-Murcia JA. Adaptation and validation to Spanish of the exercise addiction inventory (EAI). Psicothema. (2013) 25:377-83. doi: 10.7334/psicothema2013.21
77. Bush HM, Williams RGA, Lean MEJ, Anderson AS. Body image and weight consciousness among South Asian, Italian and general population women in Britain. Appetite. (2001) 37:207-15. doi: 10.1006/appe.200 1.0424

78. Schaefer LM, Burke NL, Anderson LM, Thompson JK, Heinberg LJ, Bardone-Cone AM, et al. Comparing internalization of appearance ideals and appearance-related pressures among women from the United States, Italy, England, and Australia. Eat Weight Disord. (2019) 24:947-51. doi: 10.1007/s40519-018-0544-8

79. Rossi R, Socci V, Talevi D, Mensi S, Niolu C, Pacitti F, et al. COVID19 pandemic and lockdown measures impact on mental health among the general population in Italy. Front Psychiatry. (2020) 11:790. doi: 10.3389/fpsyt.2020.00790

80. The Japan Times. School Closures in Japan May Be Fueling Internet and Game Addictions. The Japan Times. (2020). Available online at. https://www. japantimes.co.jp/news/2020/05/08/national/school-closures-japan-internetgame-addiction/ (accessed May 8, 2020).

81. Roncero C, Vicente-Hernández B, Casado-Espada NM, Aguilar L, GamonalLimcaoco S, Garzón MA, et al. The impact of COVID-19 pandemic on the castile and leon addiction treatment network: a real-word experience. Front Psychiatry. (2020) 11:575755. doi: 10.3389/fpsyt.2020. 575755

Conflict of Interest: The authors declare that the research was conducted in the absence of any commercial or financial relationships that could be construed as a potential conflict of interest.

The handling editor declared a shared affiliation with several of the authors MG-M, AV, and EA-A at time of review.

Copyright (c) 2021 Dores, Carvalho, Burkauskas, Simonato, De Luca, Mooney, Ioannidis, Gómez-Martínez, Demetrovics, Ábel, Szabo, Fujiwara, Shibata, Ventola, Arroyo-Anlló, Santos-Labrador, Griskova-Bulanova, Pranckeviciene, Kobayashi, Martinotti, Fineberg, Barbosa and Corazza. This is an open-access article distributed under the terms of the Creative Commons Attribution License (CC BY). The use, distribution or reproduction in other forums is permitted, provided the original author(s) and the copyright owner(s) are credited and that the original publication in this journal is cited, in accordance with accepted academic practice. No use, distribution or reproduction is permitted which does not comply with these terms. 